\title{
A NEW ELECTRICAL TELEMETER.
}

\author{
By Burton McCollum and O. S. Peters.
}

\section{ABSTRACT.}

Development work has been in progress for several years at the Bureau of Standards on an electrical telemetric device suitable for the measurement of strains, forces, displacements, and accelerations, with the view of making an instrument remote reading and remote recording, and at the same time adapted to the measurement of quantities that are rapidly varying in value. Satisfactory progress has been made and sufficient accuracy and stability obtained for many kinds of engineering measurements. For its operation this device deperids upon the displacement-resistance characteristic or corresponding pressure-resistance characteristic of a stack of carbon plates. Means for mounting such stacks have been devised that enable accurate and dependable calibration and give sufficient stability to readily withstand the shocks due to ordinary handling.

Practical applications so far made consist of the following: (I) Measurement of loads in airplane stay cables during flight, (2) measurement of strains in airship girders during construction, (3) tests of bridge members subjected to live loading, (4) tests of airship girders and bridge members in the laboratory, (5) measurement of pull on pressure arm of dynamometer; and (6) measurement of pressure.

The chief advantages obtained over instruments heretofore available for similar purposes are that simultaneous records or readings can be made of strains, forces, and pressures occurring at a number of widely separated points, and that rapidly varying values can be photographically recorded in their true proportions. Measurements can also be made in places which are inaccessible during tests.

\section{CONTENTS.}

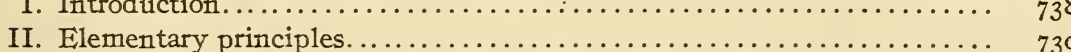

I Electrical contact elements in Wheatstone bridge circuit......... 739

2. Reasons for erratic performance of resistor elements heretofore used 742

3. Hysteresis effects due to mechanical friction............. 743

4. New design eliminates erratic performance and hysteresis effects.. 743

5. Method of obtaining linear characteristics.............. 745

III. Construction and testing of carbon resistor elements. . . . . . . . . 748

I. Conditions necessary for stability of resistance . . . . . . . . . 748

2. Conditions necessary for elimination of hysteresis.......... $75^{\text {I }}$

3. Displacement-resistance characteristics of carbon resistors...... $\quad 75^{2}$

4. Method of obtaining straight-line calibration ............ 755

5. Kind and form of carbon best suited to resistors........... 756

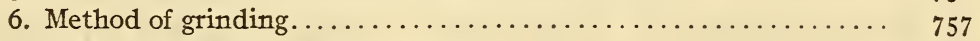

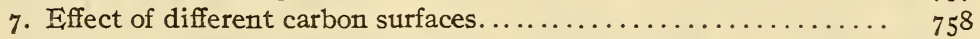

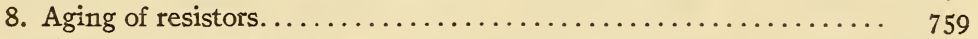

9. Time tests of resistors............................... 760

Io. Reproduction of vibrating stresses by carbon resistors......... $76 \mathrm{r}$

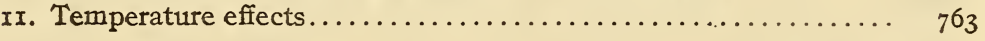


IV. Electric Page.

I

I. Load indicator for flexible members................... $7_{73}$

2. Strain indicator for rigid members.................. $7 \sigma_{5}$

3. Electrical circuits for indicating or recording measurements..... 768

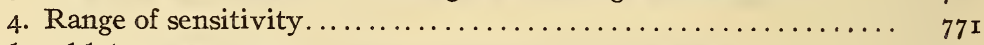

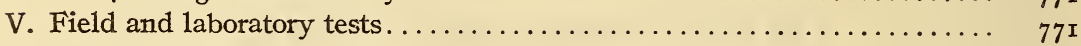

I. Airplanes. . . . . . . . . . .

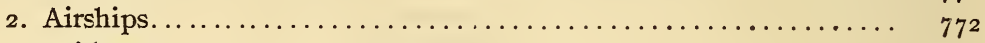

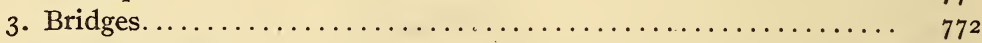

4. Dynamometers ................................... 774

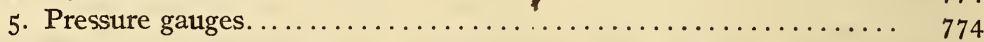

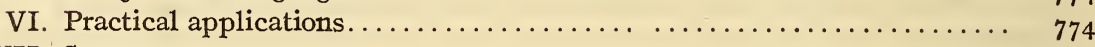

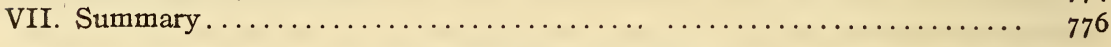

\section{INTRODUCTION.}

In this paper there is described a type of electrical telemeter adapted to making a variety of physical measurements of importance in scientific and engineering work, such as strains in structural members, pressures, small displacements, and accelerations. One of the more important applications of this new instrument, and one which well illustrates its utility, is that of measuring strains in structural members. The strain gauges at present available for measuring strains in structural members are subject to rather serious limitations with respect to the information which they will yield, more especially those of the indicative type. In measuring strains in structural members by means of these gauges a displacement in a small portion of the member under test is used as a basis of measurement. Since this displacement is extremely small, any instrument designed for reading in the usual way by a pointer or other indicator must have interposed between the pointer and the terminals in contact with the test member an amplifying mechanism to "multiply the movement several hundred fold. In the use of these mechanical amplifying arrangements it has not been possible to eliminate large hysteresis effects due to friction in the moving parts, so that accurate indications are not obtainable of the strains accompanying reversal of dynamic stress, such as might be found in bridge members. In addition, because of the inertia of the moving parts, such devices are not capable of giving even approximate indications of stresses of short duration or of harmonic stresses caused by vibrations. The inertia of the moving parts simply causes the strain to be averaged and gives the mean value. Where steady loads only are applied, this is sufficient, but in all cases of structures subjected to live loading the indication of the average strain often falls far 
short of what is necessary to determine the true condition of the stresses in the member.

Furthermore, if strains due to transient stresses of short duration or high-frequency stresses are to be measured accurately, some sort of recording device must be used, since it is not possible to read such strains directly even if an instrument were available which would indicate them accurately. Among engineers interested in structural-materials testing there has long been felt the need of an instrument capable of more extended application than the usual mechanical strain gauges, and particularly one which would correctly measure and record the strains accompanying high-frequency stresses and transient stresses of short duration. This need has been met, in part, with photographically recording instruments, the entire mechanism of which was devised to clamp to the member under test. Recording devices of this type, however, are subject in use to the vibrations of the structure to which they are attached, are incapable of application in many places on account of their size, and as an additional limitation records can not conveniently be obtained on a number of structural members simultaneously.

The object of this paper is to describe the fundamental principles and applications of an instrument that has been developed with the view of overcoming in a satisfactory manner the limitations set forth in the preceding paragraphs and which, as previously mentioned, has also numerous other applications than to the measurement of strains in structural members. Briefly, it can be made either remote reading or remote recording and the indicating or recording portion of the mechanism readily located at any convenient point at a distance from the member under test where it will not be affected by vibration or shocks. In addition, records of the strains in a number of members can be taken simultaneously, so that a correct knowledge may be had of the distribution of stress in various elements of a structure and a great saving of time effected where large numbers of readings or records are to be taken.

\section{ELEMENTARY PRINCIPLES.}

The electrical telemeter here described depends upon the wellknown fact that if a stack of carbon plates is held under pressure a change of pressure will be accompanied by a change of electrical resistance and also a change of length of the stack, both of which are reversible, the stack of plates under change of pressure per- 
forming like an elastic body. If, therefore, suitable terminal pieces or mountings for the stack of plates are supplied which can be attached to a structural member at two points spaced some distance apart, the application of stress in the direction of the line joining the terminal pieces, with the resulting strain, will change the length of the stack and also the electrical resistance on account of the change of pressure. It thus becomes possible with proper arrangements to obtain an indication of the amount of strain in the structural member, and in all cases where stress is proportional to strain to establish a definite relation between stress and the electrical resistance of the carbon stack. This resistance can readily be measured at any convenient point by running wire from the terminals of the carbon resistor to a suitable measuring instrument, which furnishes the highly desirable remote reading or remote recording feature previously mentioned. Means have been devised for calibrating the measuring instrument directly in terms of strain or force as seems desirable. It is obvious that by proper mountings strains or forces from almost any source are readily measureable, as well as those from structural members.

The idea of utilizing the displacement resistance characteristic or the correlated pressure resistance of a stack of carbon plates for making engineering measurements is not new. Numerous measurements have been made in this way in the past, but on account of hysteresis effects and the nonlinear character and instability of the calibration the accuracy obtained was low. The means whereby these defects have been overcome to an extent sufficient to give a degree of accuracy quite ample for many classes of engineering measurements are fully set forth in this paper.

\section{ELECTRICAL CONTACT ELEMENTS IN WHEATSTONE BRIDGE CTRCUIT.}

For the sake of clearness the elementary principle on which the new telemeter functions is shown in simple diagrammatic form in Figure I. Here $I$ is a portion of the structural element, the strain in which is to be measured; 2 and 3 are terminal blocks rigidly attached to the structural element; and 4 is a series of carbon disks under pressure, forming a device the resistance of which varies if the pressure is changed. It will be seen that if the member $I$ be subjected to stress either of tension or compression there will be a relative displacement of the terminals 2 and 3 , which will give rise to a change in the pressure exerted by the plunger 5 on the resistor element 4 , resulting in changes in resist- 
ance of the latter. If the apparatus is properly constructed, these resistance changes will bear a definite relation to the strain in the member under test and will therefore afford a measure of such strain from which the stress can be determined.

Figure 2 shows in principle an arrangement whereby the strain in the test member may be read directly on an indicating instrument at any convenient point. The displacement resistance de-

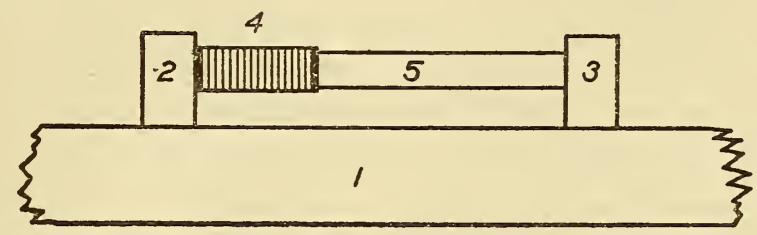

FIG. I.-Diagrammatic illustration of principle of carbon strain gauge.

vice 4 is placed in one arm of a Wheatstone bridge, the other three arms of which are 6,7 , and 8 . The bridging instrument 9 , which may be a milliammeter or oscillograph element, serves to indicate the extent of any unbalance in the bridge circuit. The battery $I 0$ energizes the bridge circuit, and the current is regulated by the variable resistance $I I$. The resistances 6,7 , and 8 are so adjusted that the bridge is balanced when the stress to

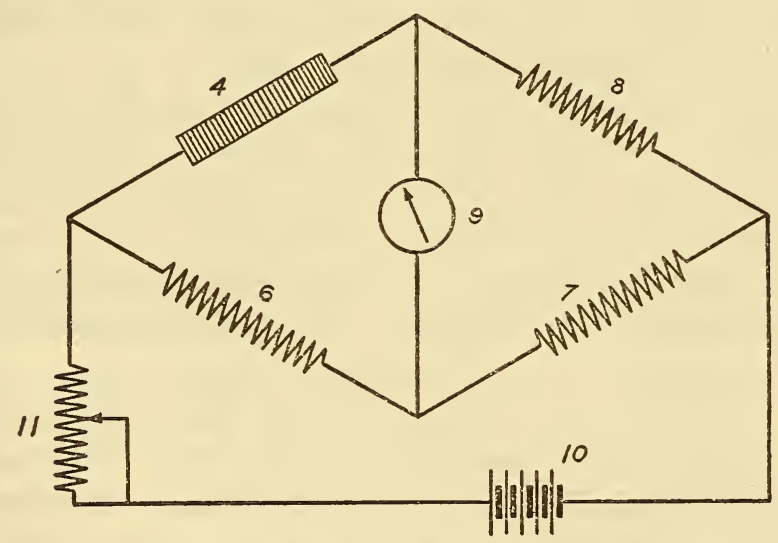

FIG. 2.-Diagram showing principle of connecting single element resistor in Wheatstone bridge.

be determined is zero and the bridging instrument 9 will give no indication. Then, when the test member is placed under stress the changes in the resistance of the displacement-resistance device 4 will destroy the balance of the bridge and the extent of the unbalance, and therefore the strain will be indicated by the bridging instrument 9 , which may be calibrated to read directly the strain in the member. 


\section{REASONS FOR ERRATIC PERFORMANCE OF RESISTOR ELEMENTS HERETOFORE USED.}

As stated previously, numerous attempts have been made to apply this principle but without success. A serious difficulty was encountered in the fact that carbon-contact resistances as heretofore constructed have shown a more or less erratic performance, their resistances varying from time to time, and the sensitivity or change of resistance for a given change of pressure varying greatly. A careful study of the cause of this instability has been made, and it is found that if two or more pieces of carbon be placed in contact and subjected to a certain pressure there will be a definite relationship between the resistance and the pressure as long as the points at which contact between the separate pieces occur remain absolutely the same. If, however, there is the slightest change in the number or location of the areas of contact, there will be sudden and erratic changes in resistance, as well as in sensitivity to further variations of pressure. These changes in the number and location of the contact areas may occur if the contact areas are stressed beyond the elastic limit, resulting in crushing, or they will occur in case the slightest move is made in a tangential direction between two adjacent surfaces in contact. Such a tangential displacement, even though very small, will cause large changes in resistance.

The reason, therefore, why these devices have in the past shown erratic performances is that the construction has been such as to permit either slight lateral displacements or permit the pressures at times to become sufficiently great to cause crushing of the contact surfaces. To overcome these difficulties several conditions must be realized. First, the surfaces in contact should be ground flat to a sufficient extent to give a relatively large area to the actual contacts, as in this way the danger of stressing these contact areas beyond the elastic limit of the carbon is reduced greatly. It is further necessary to so mount the carbon plates that it will not be possible to set up under ordinary conditions of use a shearing stress across the contact surface. In addition, the apparatus must be so constructed that the variations of pressure under normal conditions of working will not be sufficient to give rise to permanent change of conditions at the contact surfaces. The essential features of the design of the apparatus whereby these results are accomplished will be described later. 


\section{HYSTERESIS EFFECTS DUE TO MECHANICAL FRICTION.}

Another serious difficulty that has been encountered in previous attempts to utilize carbon-contact resistances for strain-gauge measurements arises from the marked tendency of the apparatus to show hysteresis effects so that the indications for a given stress will differ greatly, depending upon whether the particular stress is approached from a higher or lower value. It has been heretofore believed that this tendency to show hysteresis effects was an inherent property of carbon-contact resistances. An extensive study of this subject, however, has shown that such is not the case, and that the hysteresis effects heretofore observed have been due to mechanical friction in the mountings and terminal apparatus used to connect the carbon resistors to the member under test. If these terminal connections are properly designed so as entirely to eliminate mechanical friction, the hysteresis effects substantially disappear.

\section{NEW DESIGN ELIMINATES ERRATIC PERFORMANCE AND HYSTERESIS EFFECTS.}

The essential features of design of an apparatus whereby the difficulties above mentioned, due to erratic performances and hysteresis effects, are eliminated are shown in Figures 3 and 4 , these being side and end views, respectively, of the apparatus. Here the displacement-resistance device 4 , consisting of carbon

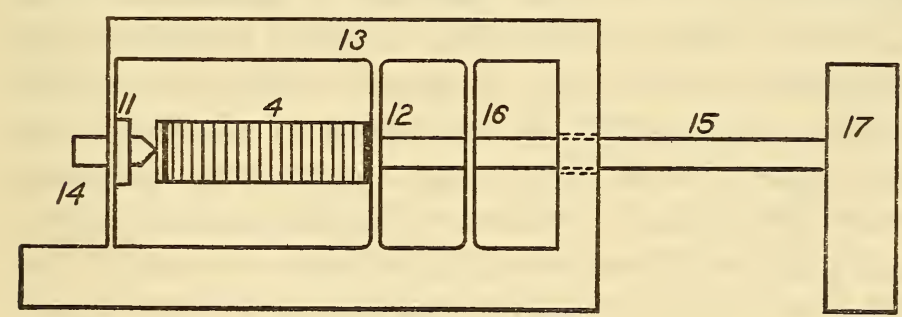

FIG. 3.-Method of mounting single-element resistor for strain gauge (side view).

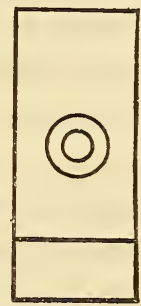

Fig. 4.Strain-gauge mount (end view).

disks laid in contact, is held pressed between the two rather stiff plates or diaphragms $I I$ and $I 2$, the plates being fixed at their outer extremities to the inclosing frame 13 . A set screw 14 is provided to adjust the initial pressure on the pile of carbon disks to a comparatively high value, it being obvious that if the disks are held together under considerable pressure the tendency 
for transverse displacement to occur will be greatly reduced. On the other hand, the higher the pressure on the disks the smaller will be the sensitivity to variations of pressure. Care must be taken, therefore, to make this initial pressure not too high, as by so doing the sensitivity will become too low for practical purposes. Furthermore, this initial pressure must be kept well below the elastic limit of the carbon disks at the points of contact. It is desirable, however, to make this initial pressure as high as these two considerations will permit. A plunger 15 is connected at one end to the plate $I 2$ and passes through a third plate $I 6$ and is firmly connected thereto. The inclosing frame I3 may constitute one of the terminal pieces, corresponding to 2 of Figure I, which is to be rigidly connected to the member under test. The plunger $I_{5}$ is extended to the other terminal $I 7$, corresponding to 3 of Figure $\mathrm{I}$, which may be simply a solid terminal piece or may be made up exactly like the part just described.

It is characteristic of a plate or diaphragm mounting of the kind described above that it yields readily when force is applied near the center and normal to the plane of the plate, but is substantially rigid and unyielding when force is applied tangentially to this plane. It will be seen, therefore, that the plate type of mounting, when used for mounting both the displacement-resistance device 4 and plunger ${ }_{5}$, accomplishes two purposes. The plunger being entirely supported by the plates $I 2$ and $I 6$, its small necessary displacement in an axial direction is permitted by a slight warping of the plate and all sliding contacts are eliminated and hence, for reasons given above, hysteresis effects are entirely avoided. Further, the rigidity of the plates in all directions, except parallel to the axis of the plunger, is so great that tangential motion of the contact surfaces of the displacement-resistance device 4 relative to each other, due to shocks or lateral forces on the plunger that may occur under ordinary conditions of use, is prevented. Consequently, permanent changes of resistance do not occur.

It is seen that in normal operation the plunger $I_{5}$ is connected to the two terminals $I 3$ and $I 7$, which in turn are rigidly connected with the member under test, and when the member is subjected to stress there will be a slight movement of the plunger. If the plate $I I$ is made too rigid in the direction of this displacement, there will be very great variations in pressure on the displacement-resistance device 4 , which if too great will give rise to permanent changes in resistance as explained above. In order 
to prevent this, both $I I$ and $I 2$ are made sufficiently yielding, so that the small displacement to which the plunger is subjected in use, which can readily be predetermined, will give rise to a variation of pressure on the displacement-resistance device 4, which is small compared to the initial pressure permanently applied thereto. It is important that the plates $I I, I 2$, and $I 6$ and corresponding parts in subsequent drawings be made integral with the frame $I 3$, so as to prevent all possibility of sliding friction at these points.

Numerous modifications of the design above described have been used, but they all conform to the essential principles here set forth.

\section{IIETHOD OF OBTAINING LINEAR CHARACTERISTICS.}

A third difficulty heretofore encountered, and one of considerable importance in practical engineering work, grows out of the fact that the resistance of a series of carbon contacts is not a linear function of the displacement of the terminals nor of the pressure applied thereto. This makes it very difficult to correct for the zero shift in the-bridging instrument and to provide for multiple ranges in the indicating apparatus. As a further result of this nonlinear relationship any factor which causes a change in any part of the apparatus will introduce errors, the magnitude of which depends on the position of the pointer on the scale, and which consequently can not be taken into account by corrections and correction factors. This characteristic is inherent in carboncontact resistances, but an arrangement has been devised whereby this tendency may be completely rectified and the apparatus caused to give strictly linear indications of stress and strain.

The principle whereby this result is secured is shown in Figure 5. Here one resistance unit 20 made up of conductors, preferably consisting of annular rings placed in contact, is held in place by being pressed between the plates 22 and 24, and another $2 I$ between the plates 24 and 26 , the two units being insulated by bushings 25. These two units are connected together electrically by the wire 27 . A plunger 28 is connected preferably near the center of the plate 24 at the point 29 and extends to and beyond the plate 30 , to which it is also firmly fixed. This plunger then extends on to the other terminal of the apparatus, as in the case shown in Figure 3. If, now, the leads $3 I, 32$, and 33 be brought out to any convenient point at which it is desired to place the indicating instrument, it is evident that the two resistances 20 
and $2 I$ can be connected in two arms of a Wheatstone bridge, one such arrangement being shown diagrammatically in Figure 6 . The bridge may be balanced by adjusting the relative resistance of the two remaining arms 6 and 7 of the bridge. It will now be seen that if a displacement be applied to the plunger 28 of Figure

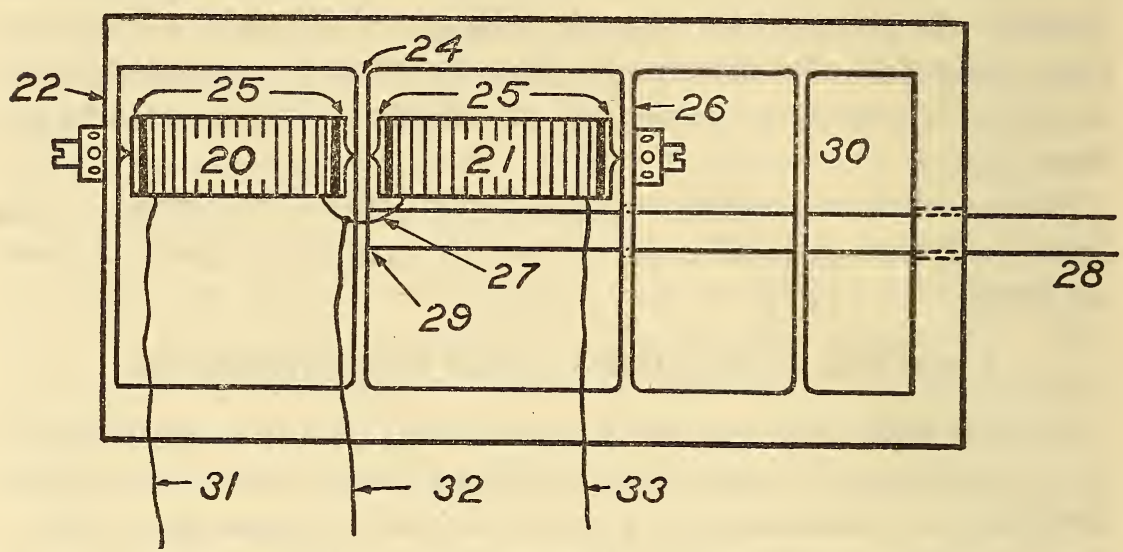

FIG. 5.-Method of mounting double-resistor type of strain gauge.

5 in an axial direction, the pressure on one of the units will be increased and on the other decreased, both of which effects tend to upset the balance of the bridge and produce a deflection in the indicating instrument 9 .

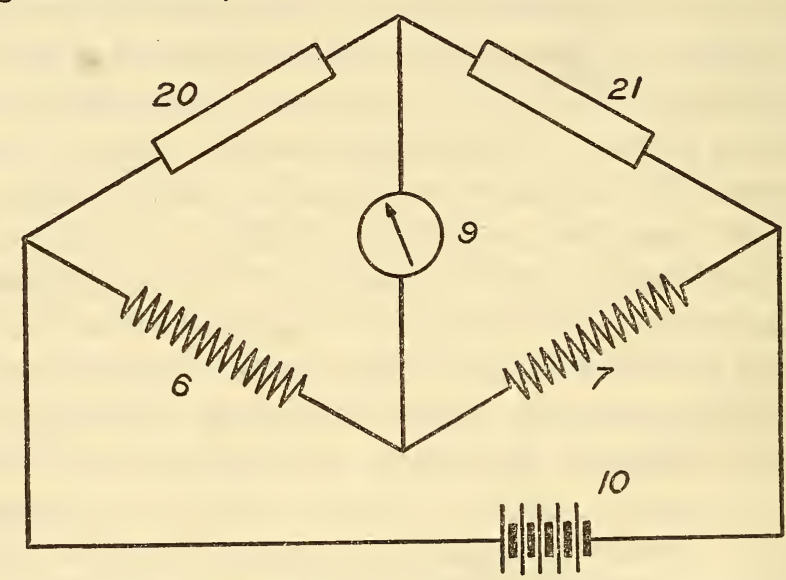

FIG. 6.-Diagram showing connection of the two elements of strain gauge in Wheatstone bridge.

By this arrangement two very important advantages are obtained. In the first place, the effects of displacement on the two resistance units is cumulative so far as disturbing the balance of the bridge is concerned; hence a given effect on the indicating instrument can be secured by so designing the apparatus as to 
use only half as much displacement on each unit as would be necessary if only one unit were used. It will be readily understood that since the relation between the resistance of the units and the displacement applied to them is represented by a curved line as previously explained, the greater the displacement range the greater will be the departure from a straight line. Hence, the construction above described, by reducing by one-half the amount of change required for a given effect on the instrument, gives a much closer approximation to the much de-

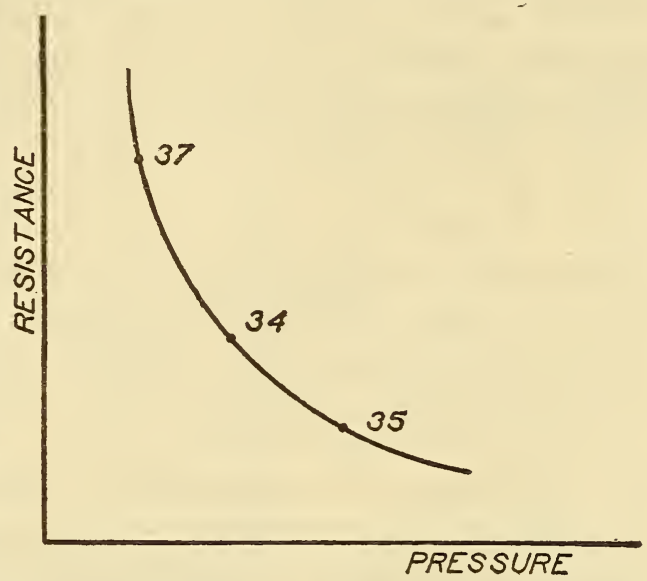
sired linear relationship. FIG. 7.-Curve showing characteristic relations between

The second important advantage of this conresistance and pressure of single stack of carbon plates.

struction contributes still further to the establishment of a linear relationship. This can best be understood by considering the characteristic curve of contact-resistance devices in general. A

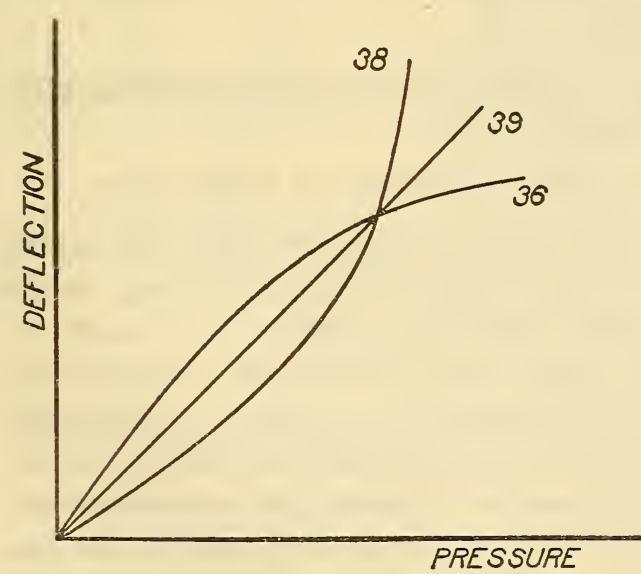

FIG. 8.-Curve showing how the curved characteristics of two stacks of plates are combined to give a linear relationship between deflection of instrument and pressure or displacment being measured. typical form of such curve is shown in Figure 7. It will here be seen that within a certain wide range the curve is similar to an equilateral hyperbola. When the pressure is small, the curve is very steep and small changes of pressure give rise to relatively large changes of resistance; but as the pressure increases the rate of change of resistance with pressure steadily decreases. Consider, now, what happens in the case of the two resistance units used as shown in Figures 5 and 6 . When no displacement is applied to the plunger 28 , the two units will be under the same pressure, 
which may be taken as corresponding to the point 34 of Figure 7 . If, now, the plunger 28 be gradually displaced in a direction to increase the pressure on the resistance unit 20 toward the point 35 , the rate of change of resistance with displacement will have a certain value at start, but will gradually fall off with increasing pressure resulting from the displacement. The effect on the bridge balance, and therefore the effect on the instrument, will vary with the pressure according to a law represented by the curve 36 of Figure 8, the curve bending off toward the pressure axis. In the case of the resistance unit $2 I$ the pressure will be decreasing toward the point 37 , and from Figure 7 it will be seen that the rate of change of resistance with pressure will increase as the displacement of the plunger increases. The effect of this on the indication of the instrument will be as represented by curve 38 of Figure 8 which bends upward toward the axis representing the deflection of the instrument. Since, as explained above, the two effects are cumulative, the resultant effect is proportional to the mean values of the ordinates of these two curves and is shown for a particular case by the curve 39 of Figure 8 , which indicates that the deflection of the instrument due to these two superposed effects is substantially a linear function of the applied stress. In Section III there is given a detailed description of some practical embodiments of the principles above set forth, together with a discussion of some applications of the apparatus and results obtained thereby.

\section{CONSTRUCTION AND TESTING OF CARBON RESISTOR ELEMENTS.}

\section{CONDITIONS NECESSARY FOR STABIITY OF RESISTANCE.}

It has long been known that carbon contacts under relatively high pressure are of comparatively stable resistance as long as the pressure remains undisturbed. This knowledge was used to advantage in the present work, but preliminary experiments showed that something more was required. In order to utilize the pressure-resistance characteristic or corresponding displacementresistance characteristic of the carbon contacts, it was necessary to change the pressure, and here disturbances entered if there was the slightest lateral movement of the contact surfaces, or if the pressure exceeded the elastic limit of the carbon, causing crushing. The problem consisted then in devising a mounting for the carbon disks, such that the desired initial pressure could be applied and this pressure changed by an applied displacement through a predetermined value without disturbing the relative position of 
the contacts in any way. In Figure 9 is shown a sketch of a device which accomplishes this purpose and which was used in testing carbon contacts under various conditions. It embodies some of the essential principles of the measuring devices described later.

Referring again to Figure $9, I$ is a steel frame cut from a solid piece of metal, 2 a series of carbon contacts consisting of a number

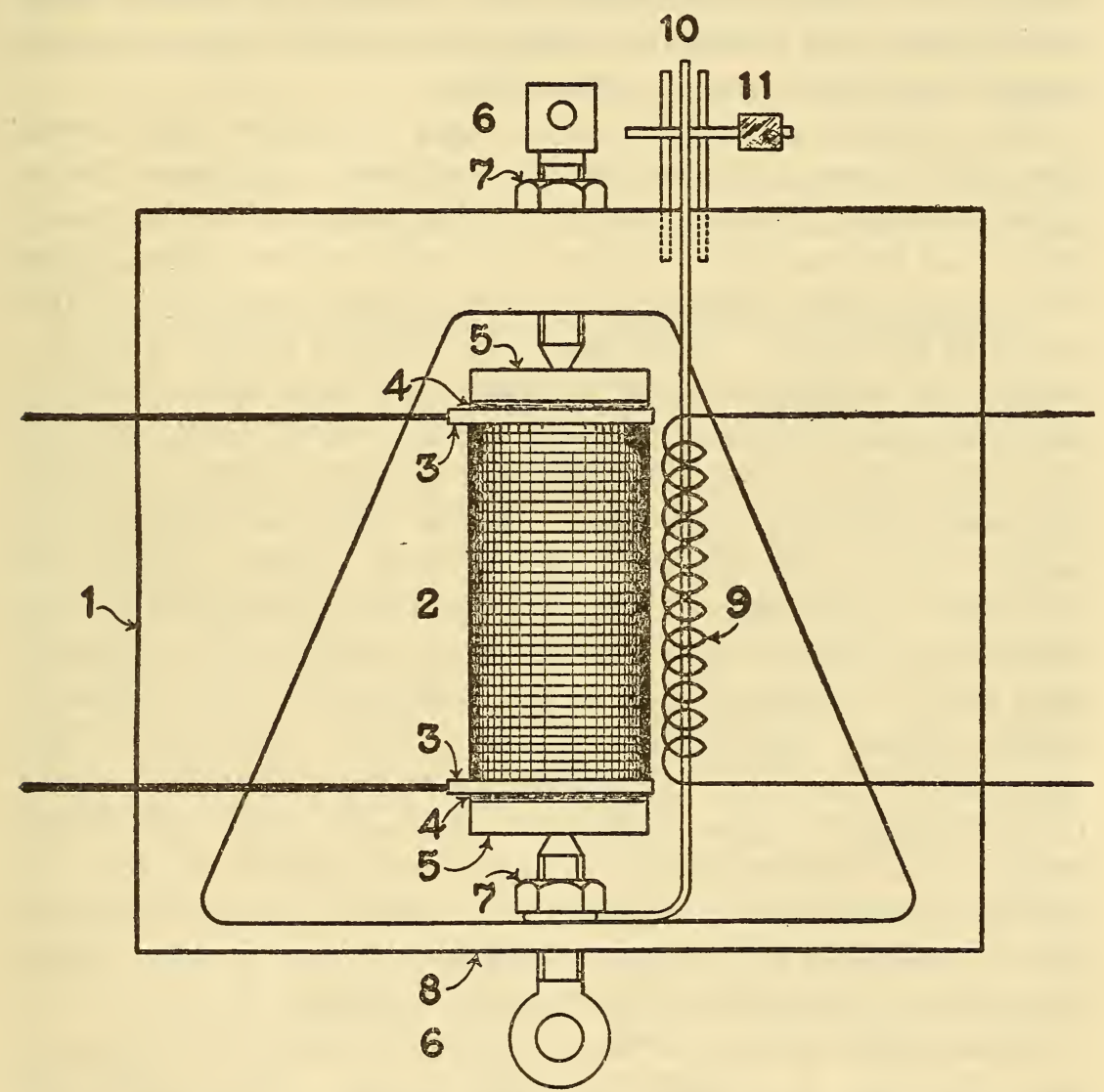

FIG. 9.-Diagram of arrangement for checking performance of single stack of carbon plates.

of annular rings described in detail hereafter, 3 a pair of brass contact disks for making electrical contact with the carbon rings, 4. a pair of mica disks insulating the carbon pile from the frame, and 5 a pair of tempered steel end pieces cupped axially to receive the round-pointed tempered steel set screws 6 , which are threaded into the frame and held rigidly by lock nuts 7 . These lock nuts are drawn tight after the desired initial pressure on the carbon is attained in order to prevent any movement of the screws in the 
thread. Part 8 of the frame is made rather thin and functions as a stiff spring which can be deflected a small amount by suspending weights from the hole in the head of the lower set screw. Part 9 is a magnetizing coil and to three small steel rods, one of which extends to the lower lock nut, the other two being set rigidly in the top part of the steel frame. Part $I I$ is a small steel roller carrying a mirror, the roller being held between the steel rods $I o$, which can be magnetized by the coil 9 , causing the roller to stick and eliminate any possibility of slippage when the long rod moves longitudinally with respect to the others.

The operation is as follows: A stack of carbon rings being assembled between the set screws, the screws are drawn up to a predetermined pressure shown by the resistance of the stack, which can be measured through the brass contact pieces. The lock nuts are then tightened to prevent further movement of the screws in the thread. With the frame clamped rigidly in a vise, weights are suspended from the lower set screw which deflects the spring 8 and relieves part of the pressure on the stack, causing an increase of resistance. Weights can be added until the desired maximum deflection is produced. As the deflection increases the longer of the three rods $x o$ is drawn down, causing rotation of the roller $I I$, the amount of the deflection being measured by the rotation of a beam of light reflected from the mirror on a groundglass scale. A magnification of the deflection of ro,ooo times is easily attained, enabling easy reading of the deffection if the dimensions of the roller and the distance to the scale are known. In this manner a large number of tests were made, the results being shown in a succeeding section of this paper in the form of several displacement-resistance curves; that is, change of resistance as compared with change of length of a stack of rings, which is a more convenient form than pressure-resistance curves.

The absolute accuracy of the method of measuring the displacement depends, of course, upon the accuracy with which the diameter of the roller is measured, whether it is cylindrical, and other factors. The errors may be considerable, but at the same time results can be repeated very closely which is valuable in checking the stability of the stack and the effect of repeated cycles of displacement.

The thing which it is desired to emphasize at this point is that a device of the character described above contains the elements necessary for stability of the electrical resistance of the stack of rings. The pressure is applied axially, and the only freedom of 
motion is axial, there being no rotating or shifting parts. Changes of pressure in an axial direction may, therefore, be made without disturbing the contacts in any way. It is assumed, of course, that the rings have nearly parallel plane faces and are assembled with faces perpendicular to the axis of the stack, and the mechanical construction is accurate throughout. With these conditions fulfilled it has been found that the resistance will retain its value within I per cent through hundreds of cycles of change of pressure within definite limits and will readily withstand shocks such as are likely to be encountered in ordinary handling. Where subjected to vibration amounting to hammer blows, however, special mountings are necessary. Some experimental types have been tried with fair success but are not ready to be reported upon at this time.

\section{CONDITIONS NECESSARY FOR ELIMINATION OF HYSTERESIS.}

It was noted in connection with Figure 9 that the steel frame $I$ was cut from a solid piece of metal, making a structure free from mechanical joints and depending for resistance to distortion only on the elasticity of the material. This form of construction was evolved after numerous trials with mechanically jointed frames, all of which showed a large hysteresis loop. Changing the character of the joints changed the character of the loop, so in the end a trial was made of a structure without joints. The hysteresis loop disappeared coincidentally with the disappearance of the joints, which seemed to constitute sufficient proof that the effect lay not in the carbon but in the mountings. It is not practicable, of course, to entirely do away with contact surfaces other than those of the carbon, because pivot contacts are necessary at either end and also screws for applying pressure. By making these of properly tempered steel, however, and providing lock nuts, crushing or slipping under the pressures used can be avoided and the hysteresis reduced to a negligible amount.

The reason for the large contribution of the mechanical joints in the frame to the hysteresis effect seems to lie in the fact that where two metallic surfaces are brought together, even under considerable pressure, a force of sufficient magnitude, acting either laterally or perpendicularly, may cause movement of the parts relatively to each other. This movement takes place under more or less friction, and in making restoration the friction load must be overcome. Thus, it comes about that in a frame where the sole restoring force is due to the elasticity of the material any $63245^{\circ}-24-2$ 
slippage of this sort gives rise to a lag in the restoration, making it appear that a decreasing pressure produces something different from that obtained with increasing pressure.

It should be pointed out here that in no part of the structure can the elastic limit of the material be exceeded without producing irreversible changes in the resistance of the stack of rings. This applies particularly to the pivot points and their cups. As mentioned previously, the points should be slightly rounded to give a substantial bearing surface, and both cups and points should be tempered, preferably to a light straw color. In less degree it also applies to other parts and is a factor which must be given careful scrutiny in designing any form of strain or pressuremeasuring device using carbon contacts.

In further discussion of this subject the assemblage consisting of the series of carbon contacts, end pieces, set screws, and frame will be referred to as a carbon resistor, since in all of its applications this essential form is retained, with only minor modifications to suit particular conditions.

\section{DISPLACEMENT-RESISTANCE CHARACTERISTICS OF CARBON RESISTORS.}

The displacement-resistance characteristic of a typical stack of carbon rings is shown in Figure Io. Here the stack of rings, 42 in number in this particular case, was assembled and compressed in a frame of the type shown in Figure 9, the frame clamped rigidly in a vise, so there could be no deflection of spring 8 , and the pressure on the stack released by means of the upper set screw, which would, of course, cause the length of the stack to increase. One end of the stack being fixed, the increase of length with each diminution of pressure could be ascertained by observing the movement of the other end, which was done with a micrometer microscope. At each increment of length the resistance was also measured, the results being plotted with displacement values as abscissas and resistance values as ordinates.

In connection with this curve, which has the well-known hyperbolic form associated with pressure-resistance curves for various substances, the region $A-B$ is of particular interest, because it is there that is found the minimum of sensitivity and also of stability that can conveniently be made use of in practice. Below $A$ the stability increases, but there is such a marked decrease of sensitivity that the recording or indicating instruments used in connection with measuring devices must be of inconveniently 
high sensitivity, whereas above $B$ the sensitivity increases greatly, but the stability becomes so uncertain as to make the device subject to disarrangement from even slight shocks or vibration.

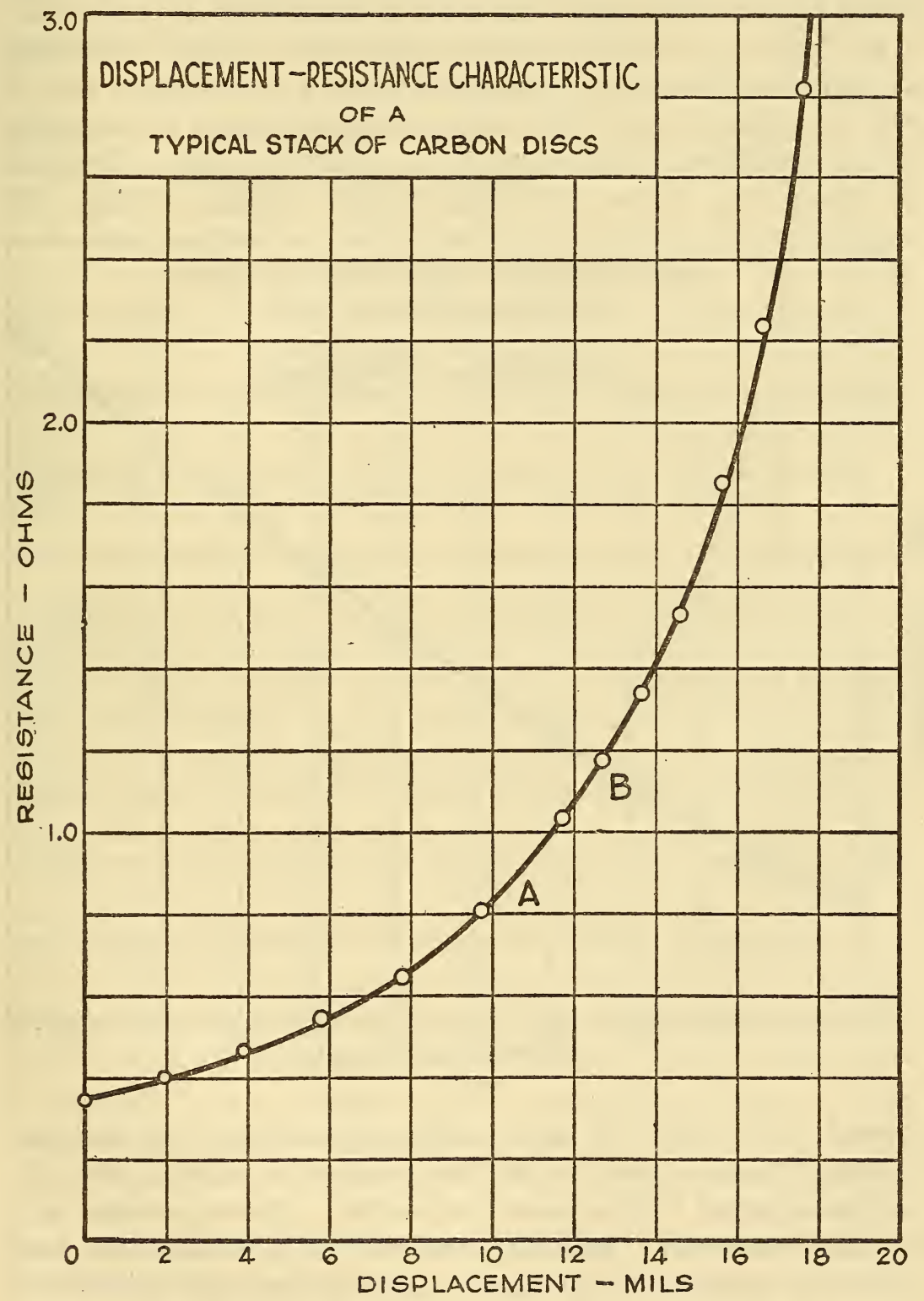

Fig. IO.

In the region $A-B$, however, which is approximately at the knee of the curve, there is a combination of sensitivity and stability that has given exceptionally good results in a number of practical 
applications. Instruments made up with resistors adjusted to operate in this region have been in use more than two years with no change in calibration greater than 2 per cent. The question of the factors which affect calibration is discussed in detail later.

In Figure II is shown a curve taken from a resistor adjusted to operate in the region corresponding to $A-B$ in Figure Io. It will be observed that the lower and upper values of resistance do not correspond to the values at $A$ and $B$ in Figure Io, but this is because the curves are from different stacks of rings. In

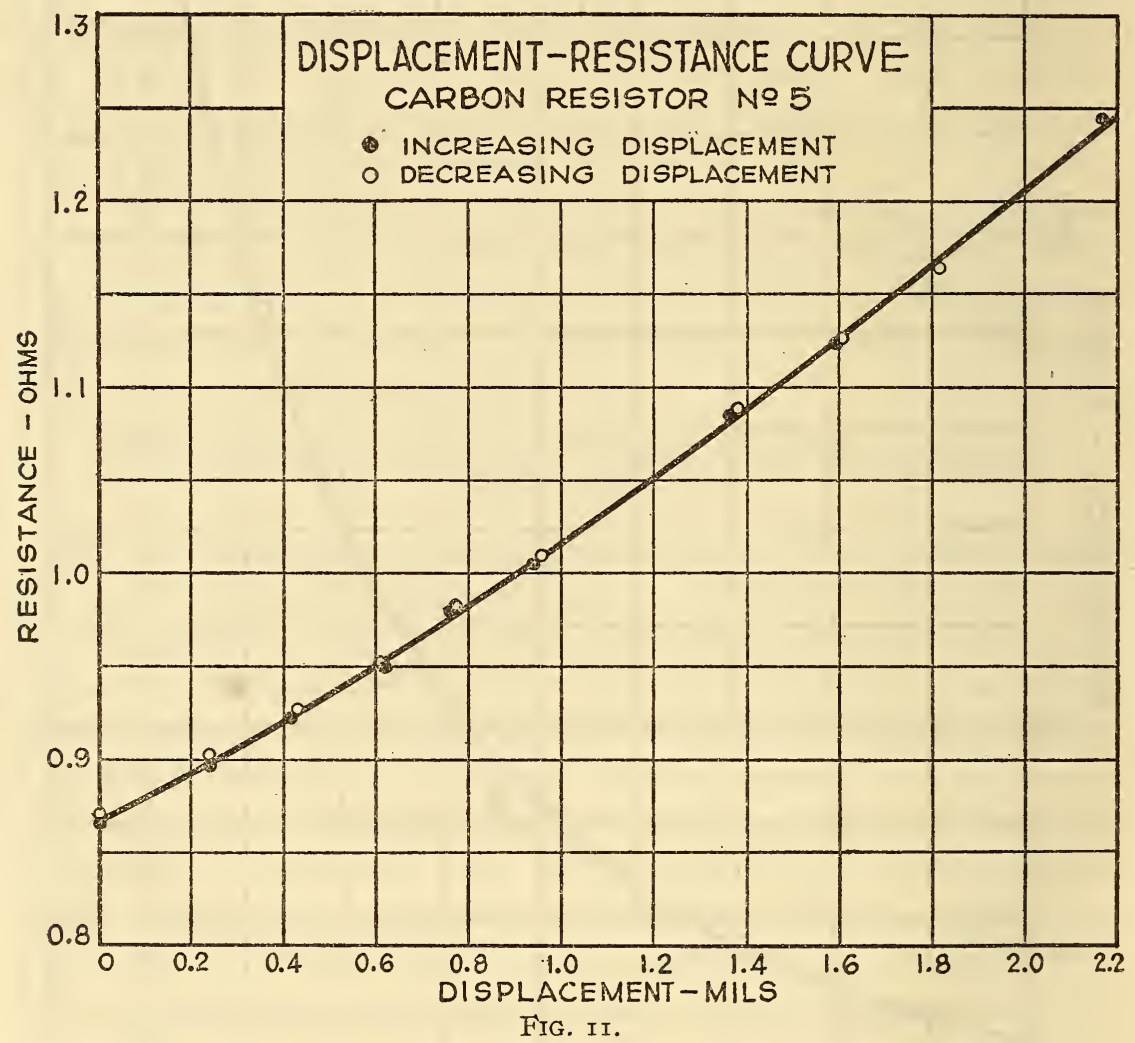

general, each stack will have a different value for the most desirable adjustment, but for practical purposes a number of stacks can be adjusted to the same value if the carbon in each is of the same character. Different stacks of rings of the same kind of carbon prepared in the same way also give slightly different shapes of displacement-resistance curve, but this is of no practical consequence as far as ordinary use is concerned. Different kinds of carbon give great differences in shape, as also do different methods of finishing the surfaces of the rings in grinding. This 
fact is of value in practical applications and is enlarged upon further along in this paper.

In Figure II the magnitude of the change of resistance is of particular interest, it being approximately 46 per cent for a change of length of 0.00217 inch, and is representative of the performance of carbon resistors in general. Attention is also directed to the coincidence of increasing and decreasing values; that is, the hysteresis effect is negligible.

It may be well to add here that, although in the tests just described the stacks were adjusted to their lower value of resistance and the length and resistance increased, the process could be reversed, the stacks being adjusted to the upper value of resistance and the length and resistance decreased. The shape of the curve is the same between the same limits, a fact which is of interest where it is desired to give the maximum range to certain types of strain and pressure measuring devices.

\section{METHOD OF OBTAINING STRAIGHT-IINE CALIBRATION.}

Referring to Figure Io, the displacement-resistance curve of a carbon resistor is roughly hyperbolic in form, and as a consequence when a single resistor is used with an indicating or recording electrical instrument having uniform scale divisions it will give a similiarly hyperbolic displacement-deflection curve. This is inconvenient, because it involves the constant use of a calibration sheet. It is much more desirable to make the instrument direct reading. Means for doing this were described in the first part of this paper, the chief feature being the use of two stacks of rings, so that in one the resistance decreases while in the other it increases. The curves of the two stacks, being similar, compensate each other, and it has been found by experiment that if the same displacement takes place in opposite directions in a pair or stacks made as near alike as practicable the readings of the instrument become a linear function of the quantity being measured.

In the practical embodiment of this principle the two stacks of rings are assembled on opposite sides of a flat spring, which is made to deflect by the force or displacement under measurement. For small amounts this deflection is proportional to the force applied, which means that the displacement of the stacks is also proportional, and the ultimate effect is to produce proportional deflections of the indicating instrument. Aside from the matter of stright-line calibration, the use of a spring between the stacks as a means of communicating forces and displacements to them 
permits the adjustment of the initial resistance of the stacks to any desired value, equal or unequal, which, in a case where stresses or strains having no reversal of sign are being measured, may be the means of greatly increasing the range of the instruments. This is the case in a load indicator for flexible members described later.

\section{KIND AND FORM OF CARBON BEST SUITED TO RESISTORS.}

This subject is one in connection with which a great deal of experimental work remains to be done. Of the large variety of carbons available only a few have so far been tested. Preliminary trials were made with soft carbon, such as that used for ordinary arc lights, but it soon became apparent that these would not give good results. In order to get a stack of a convenient value of resistance, it would have to be made inconveniently long, since the resistivity of soft carbon is low and the contact resistance between surfaces also low. Harder carbons were then made up into stacks and gave satisfactory results, the best so far being obtained with negative searchlight carbons. The experiments made up to this time have been confined largely to the searchlight carbon, chiefly because practical applications were called for long before the research work could be completed, but other carbons have been experimented with, and stacks having resistances from to to roo ohms are now available.

The searchlight carbons, being in the form of cored rods, thin sections are sawed off, the section of core removed, and the resulting annular ring ground to the desired thickness. The sawing is done in a lathe, using for a cutter a short piece of hacksaw blade which is set at an angle in a tool holder and can be advanced while the carbon rod revolves at a rapid rate. The blade wears very rapidly and must be frequently renewed. Sawing in this manner results in inconsiderable breakage and gives a ring thin enough to permit rapid finishing by grinding. The grinding is done by means of a pair of revolving cast-iron disks described in section 6 following.

The thickness of the rings is an important factor, since the total resistance of the stack for a given grade of carbon depends principally upon the number of surfaces in contact, and it is very desirable to keep the stack within reasonable dimensions. The minimum thickness that it seems practicable to use without undue fragility is about 0.020 inch. Rings can be ground to this thickness with ease, especially where there are few flaws in the carbon rods. 
A stack of 60 is about $\mathrm{I} / 4$ inches long. The outside diameter ranges from $\frac{7}{16}$ to $5 / 8$ inch and the inside diameter from $\frac{7}{32}$ to $\frac{5}{16}$ inch. The resistance ranges from 0.8 to $0.9 \mathrm{ohm}$ for the lower value and from I.2 to I.3 ohms for the upper value. Stacks of from 50 to 60 are used regularly and constitute a very convenient unit.

The use of annular rings has several advantages, the main one being that for a given resistance, and consequently a given crosssectional area, there is obtained a more stable arrangement than would result from the use of solid disks because of the larger outside diameter. The annular ring also grinds better, a solid disk tending to be high at the axis, whereas the annular ring is free from this tendency because the center is removed. There is also the matter of radiation of heat while current is passing through the stacks. The amount of heat liberated is small, of course, but at the same time it is desirable to have it radiated at the lowest practicable internal temperature, and here the annular rings have the advantage because of the greater radiating surface in proportion to contact area. On the whole, the annular ring appears to be the most satisfactory form.

\section{METHOD OF GRINDING.}

Since the construction of a considerable number of resistors involves the grinding of a large number of rings, it is desirable to have some means of turning them out rapidly. The grinding machine used for most of the work so far done consists of a pair of cast-iron disks five-eighths of an inch thick and of unequal diameters, that of the lower being 12 inches and of the upper $7 \mathrm{I} / 2$ inches. The larger disk is supported in a vertical axial bearing and made to revolve at about $60 \mathrm{rpm}$ by means of a belt running in a groove on the edge. The upper disk rests directly on the lower, with centers sufficiently eccentric to make the circumferences approximately tangential, and is held by an axial bearing. Revolving the lower, therefore, causes the upper also to revolve, resulting in a grinding motion between the two. The upper disk is bored full of holes a little larger than the carbon rings and each hole provided with a rather close-fitting steel plug about II/4 inches long, with a shoulder to prevent its coming closer to the bottom of the hole than the desired thickness of the finished carbon ring.

In operation the carbon rings are placed in the holes in the upper cast-iron disk, with the steel plugs resting on them, and the cast- 
iron disks revolved, the resulting motion of the two being such as to drag the carbon over the cast iron. Powdered emery or other grinding material is fed in between the revolving disks. After grinding one side of the rings flat they are turned over and finished from the other side. The machine as designed holds 77 rings and takes about two hours for grinding the lot.

The finished rings, while not perfectly flat with parallel faces, are so to within a thousandth of an inch on the average; that is, the thickness of opposite sides of a ring will be the same within a thousandth of an inch. While this may not be as high a degree of precision as might be desirable, rings so finished have been found to be satisfactory, and a reasonable tolerance greatly increases the speed of production.

\section{EFFECT OF DIFFERENT CARBON SURFACES.}

The use of different grades of emery in grinding the carbon rings results not only in different shapes of the displacement-resistance curve for different stacks but also in greatly different values of resistance for a given pressure. In Figure I 2 are shown some curves in the region corresponding to $A-B$ in Figure Io, which were taken from stacks of rings of the same kind of carbon but ground with different sizes of grinding material. Here curve $I$ is from a stack ground with No. 200 emery, which is one of the medium sizes. The next curve 2 is from a stack of rings that had been polished by rubbing on a carbon plate. Curve 3 is from a stack ground with No. $2 \mathrm{~F}$ emery, or the grade next coarser than emery flour. Curve 4 is from a stack of rings ground with No. 303 emery, which is fine enough to remain in suspension in water.

These curves indicate first of all that the finer-grained surfaces give much less contact resistance than the coarser-grained surfaces, and also that the rate of change of resistance with displacement is greater with the former than with the latter. The polished surface is the most sensitive of any to change of displacement. This desirable feature of high sensitivity, however, is somewhat counterbalanced by lack of stability, so in the practical applications that have been made preference has been given to the carbon with the coarser-grained surface, No. 200 emery being used for most of the grinding. The curves of Figures Io and II were obtained from stacks ground with No. Ioo emery and show sufficient sensitivity for nearly all purposes. Much work remains to be done here, however, especially on the finer grained and polished surfaces, because in certain applications they are likely 
to be very useful. The polished stack, for instance, which has a curve approximately parabolic, may prove useful in measuring physical forces which vary according to the law of squares, as does wind pressure.

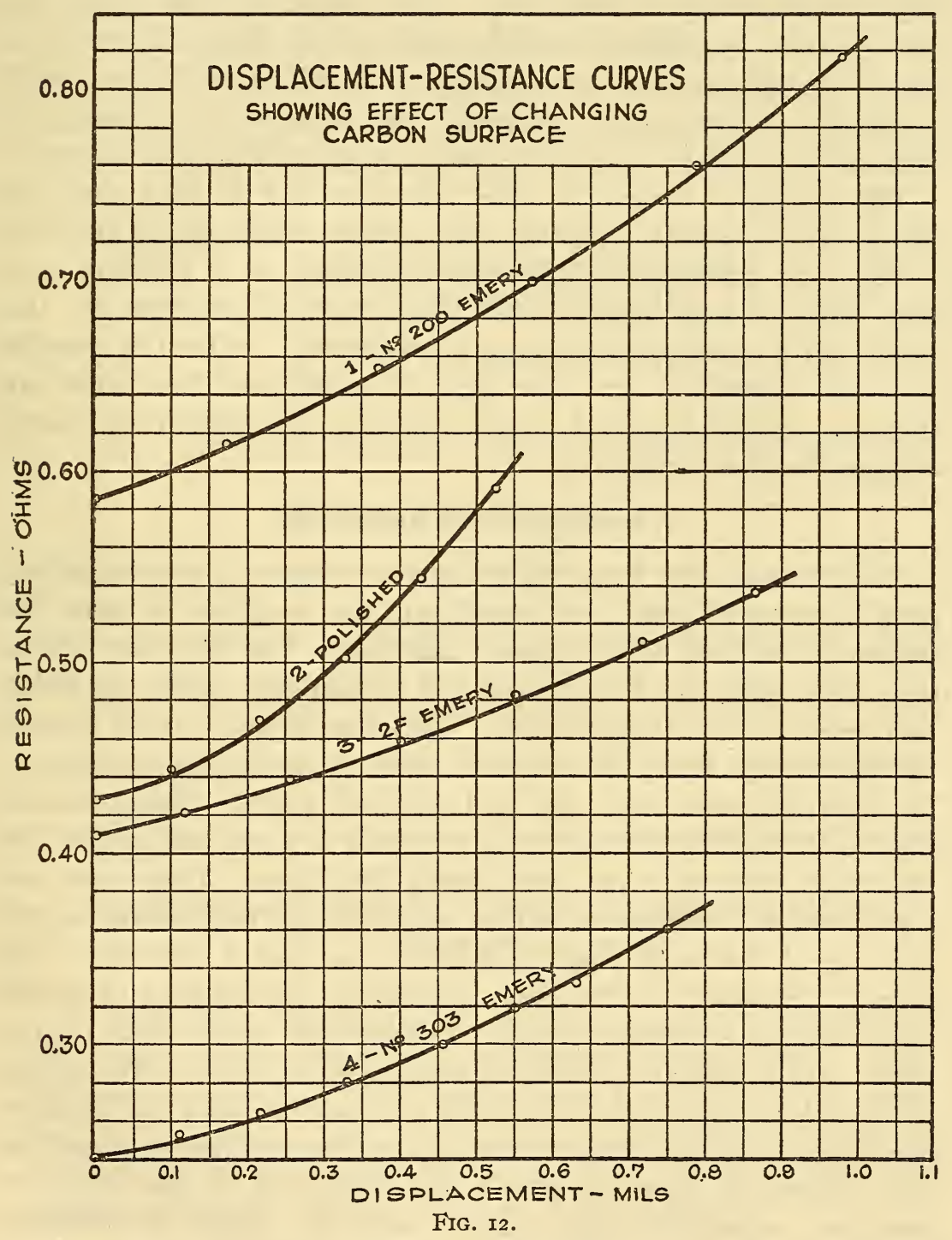

8. AGING OF RESISTORS.

When a resistor is newly assembled and adjusted there is likely to be more or less variation of the initial resistance during the first applications of change of pressure. This variation is not great, but generally takes on the character of an increase of a few 
per cent until a stable value is reached. In assembling new apparatus, therefore, it is desirable to put it through several hundred cycles before calibrating it. After the first calibration it should be checked at frequent intervals for a time to see whether any further change takes place. The factor of time enters to some extent, but after a month nearly all of the instruments so far built had reached a condition of stability such that only occasional checking was necessary, the same as is necessary in the case of all other instruments used in engineering measurements.

The apparent reason for the aging quality is that the end pieces, pivot bearings, threads, and carbon stacks all go through a slow and permanent deformation process, or a bedding into each other, which tends toward reduction of pressure on the stack and a consequent increase of resistance. After the resistor has been assembled for some time, however, and has been put through several hundred cycles covering its maximum range, changes become very small.

\section{TIME TESTS OF RESISTORS.}

There has not yet been opportunity to observe a set of resistors over a period of years, but some data are available to show the degree of stability with ordinary handling. The first case is that of a stress indicator for airplane and airship stay cables, in which two resistors were incorporated. This was in use or lying around the laboratory, being moved from place to place with no particular care for more than one and one-half years. Measurements show a change of resistance in one resistor of I per cent and in the the other of 0.2 of I per cent during that time. There was also a net change of calibration within a period of corresponding length, but not of the same date, of a little less than 2 per cent. Six other instruments of the same kind after four months of rather rough handling showed changes of calibration of less than I.6 per cent. The calibration, however, was made on some of the regular stay cables, which are rather stiff and uneven, and the changes are of the same order as the errors in making readings, so doubtless the calibration does not give a fair indication of the degree of precision attainable with carbon resistors. They do indicate, however, that even under unfavorable conditions the degree of precision is great enough for engineering purposes.

The second case is that of carbon resistor No. 5, the displacement-resistance curve of which is shown in Figure II. This resistor was assembled April 8, I92I, put through a number of 
cycles, and a displacement-resistance curve made April I4, I92 I. In assembling the top set screw was accidentally twisted off with the lock nut, so no adjustment could be made. Until July I , I 922, this resistor was handled a great deal and moved from place to place. On the latter date a second displacement-resistance curve was made, the two being plotted in Figure I3. It is there seen that the two curves coincide as nearly as could be expected. No change of appreciable magnitude occurred in $\mathrm{r}_{5}$ months, in which time no particular care was taken to prevent shocks or handling.

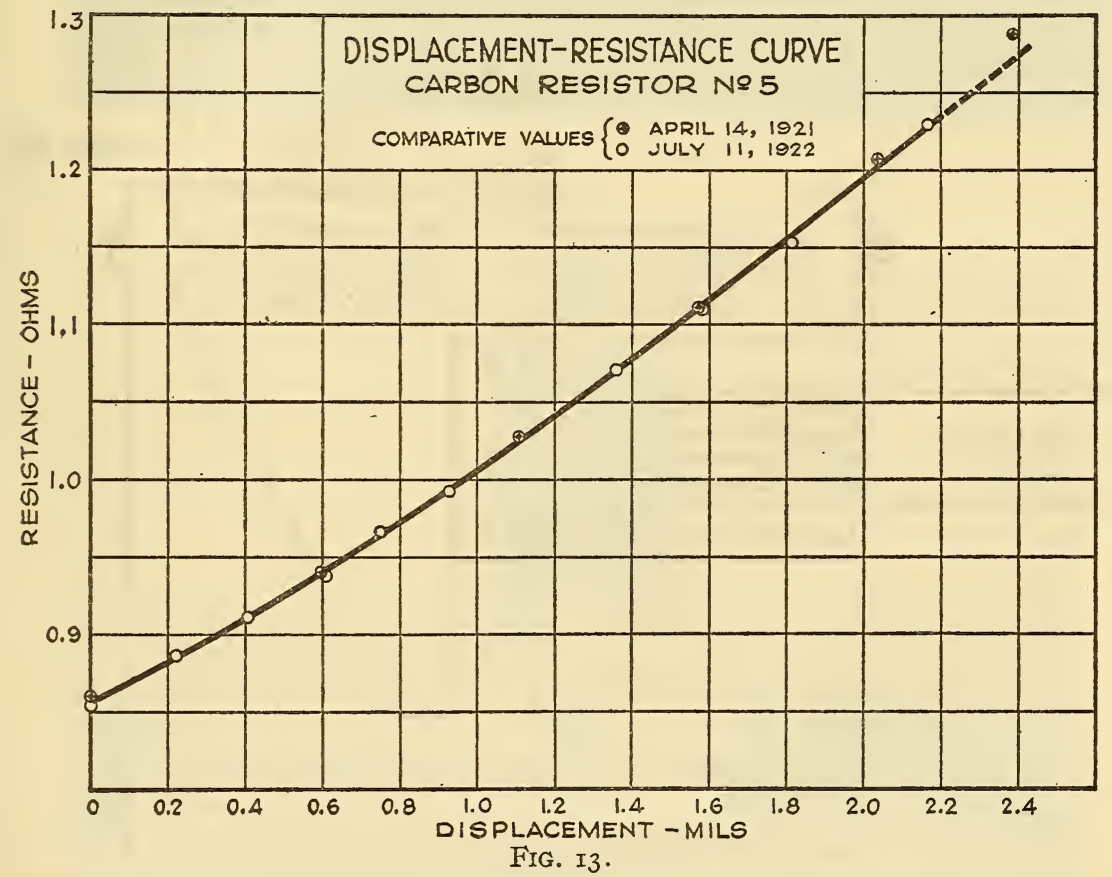

In comparing Figure $\mathrm{I} 3$ with Figure II it will be observed that the resistances are not exactly the same in the two cases. This is because in Figure II the resistance of a short pair of leads is included, while in Figure $\mathrm{I} 3$ it is not. The resistance of the leads was subtracted before plotting the curve of Figure $I_{3}$ in order to place the data for the two dates on the same basis.

\section{REPRODUCTION OF VIBRATING STRESSES BY CARBON RESISTORS.}

In order to determine something in regard to the natural period of a stack of carbon rings, a piece of apparatus was made up as shown diagrammatically in Figure I4. Here $A$ is a frame cut from a solid piece, with a tongue $B$ integral with the frame. The car- 
bon stacks are mounted on either side of this tongue, the movement of which is indicated by a roller carrying a mirror. Laminated pole pieces are provided so the tongue can be vibrated with an alternating current. The apparatus was mounted inside the cover of an oscillograph, so simultaneous records could be taken of the mechanical vibration and of the accompanying electrical vibrations of the oscillograph element, which formed the bridging instrument shown in Figure 6. The natural period of the oscillograph element was about 5,000 per second, with oil damping.

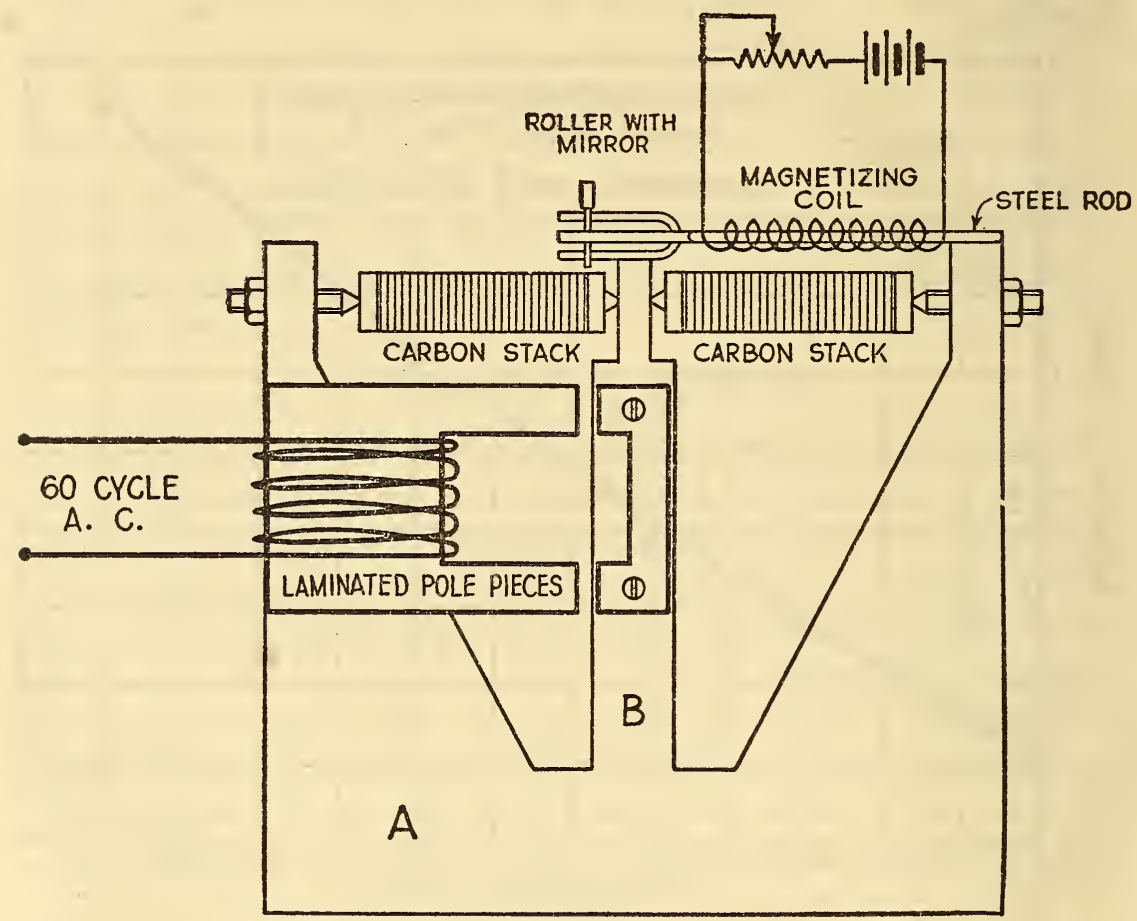

FiG. I4.-Arrangement for optically checking the performance of double-stack arrangement of carbon resistors.

Having adjusted the current in the stacks and that in the alternating-current circuit to values that would give somewhere near the same amplitude of the light spots from the mirror on the roller and that on the oscillograph element, some records were taken, one of which is shown in Figure 15 , the deflections beginning at the moment of closing the alternating-current switch. The resulting traces illustrate the building up of a forced vibration in an elastic member, the forced vibration being at the rate of $\mathrm{I} 2 \mathrm{O}$ per second, or double that of the exciting current, and the other, which is the natural frequency of the elastic tongue, at about 840 
Technologic Papers of the Bureau of Standards, Vol, 17

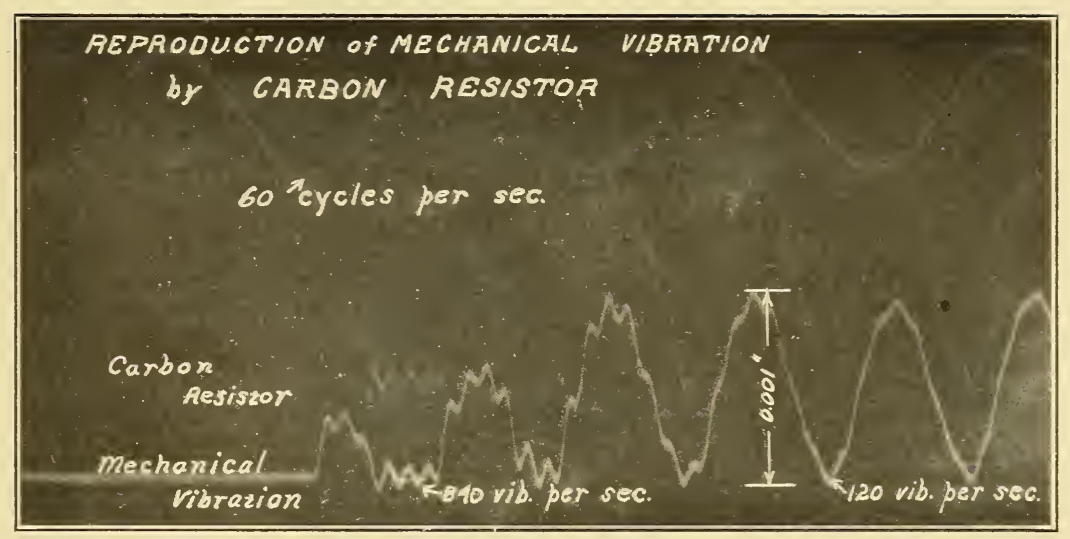

FIG. I5.-Oscillogram showing accuracy of reproduction of stress wave by carbon resistor.

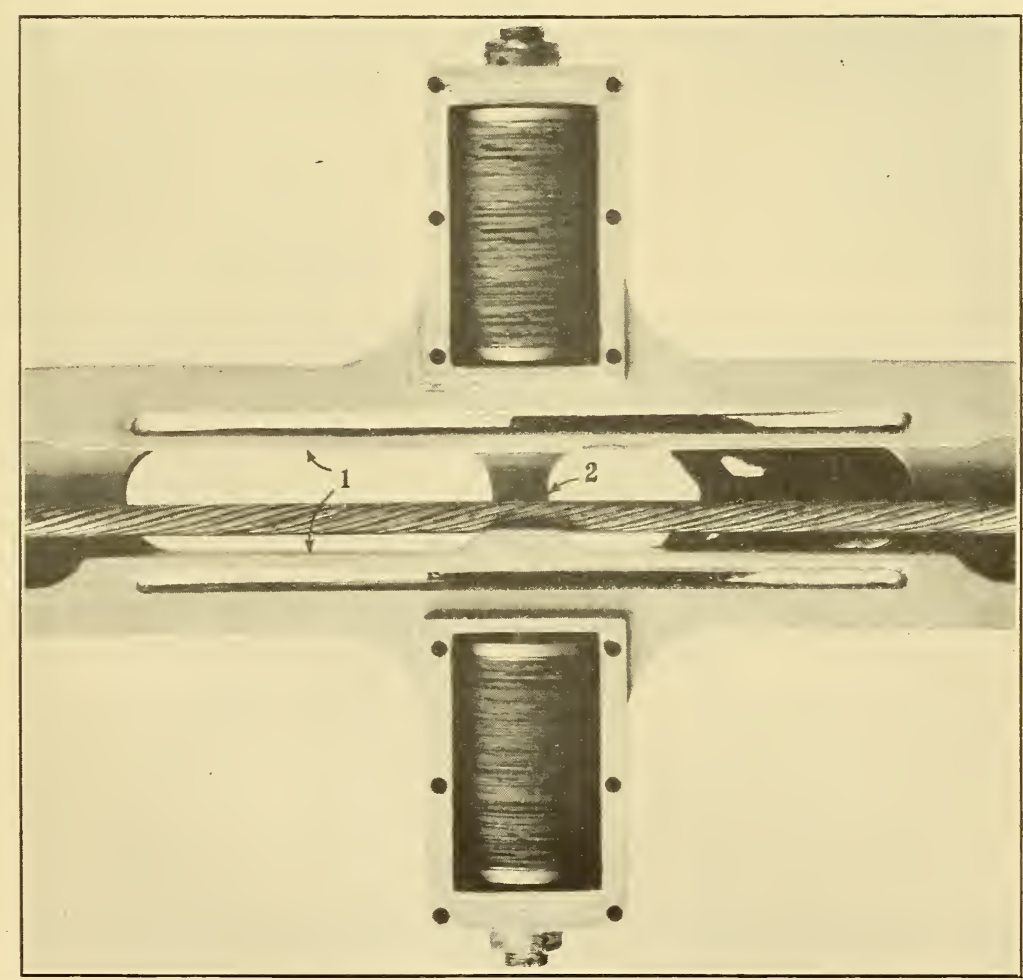

FIG. I6.-Details of arrangement of double stack strain gauge for use on flexible cable. 
Technologic Papers of the Bureau of Standards, Vol. 17

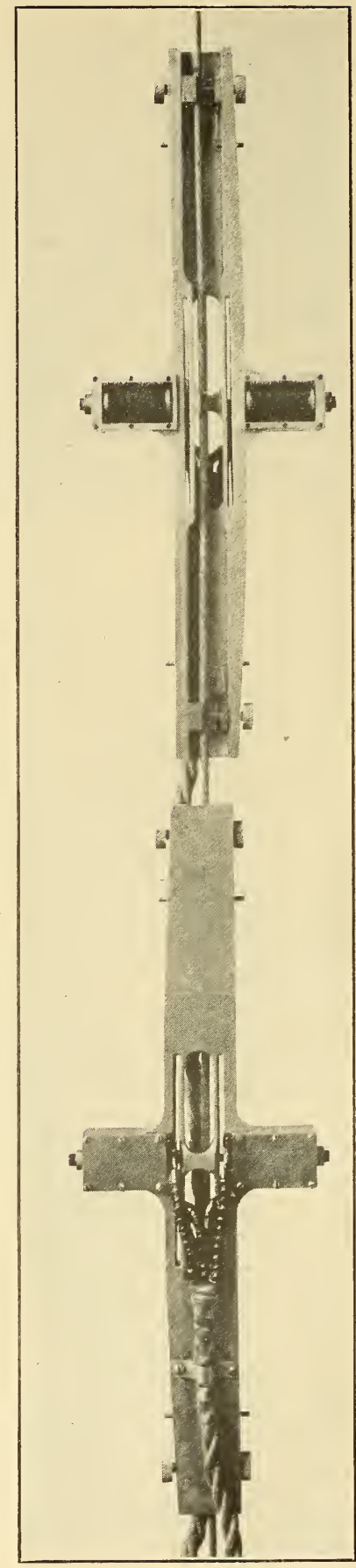

FIG. I7.-Two strain gauges mounted on single cable. 
per second. Scaling the traces near the beginning where the higher frequency is steady and also near the end where the lower frequency is steady shows the relative amplitudes to be within 5 per cent; that is, the stacks of rings reproduce the amplitudes at I 20 cycles per second and at 840 cycles per second within 5 per cent of their true values, which is within the possible error of measurement. It appears, therefore, that up to 840 cycles per second, at least, a properly mounted pair of carbon stacks can be depended upon to reproduce mechanical vibrations with sufficient accuracy for engineering purposes. Further experiments will be conducted to determine, if possible, the resonance frequency of stacks of carbon plates under the pressures normally used.

\section{TEMPERATURE EFFECTS.}

As mentioned previously, carbon resistors are subject to temperature effects, the chief effect arising from the discrepancy in expansion or contraction of the frame and carbon stack with change of temperature, which changes the pressure and therefore the resistance. Much experimental work remains to be done on this feature, but enough data are available to. show that it is small and can readily be compensated by adjustment of the electrical circuits as the temperature changes.

\section{ELECTRIC TELEMETER AS REMOTE READING AND RECORDING STRAIN AND LOAD GAUGES.}

The main problems encountered in the design of instruments involving the use of carbon resistors are discussed below, special reference being made to instruments for measuring loads in flexible members, such as airplane stay cables, to instruments for measuring strains in rigid members such as are found in steel bridges, and to methods of indicating or recording the results.

\section{LOAD INDICATOR FOR FLEXIBLE MEMBERS.}

The details of a load indicator for flexible members are shown in Figure 16 , in which a pair of resistors are mounted in a toolsteel frame formed from a solid piece. Part $I$ of the frame acts as a double spring, which is rigidly held together by the yoke 2, so that the two parts deflect together. The stacks of carbon rings occupy boxes on either side. In the end of each box nearest the spring are holes which allow the steel end pieces of the stacks to rest in cups made in the spring itself. Pressure is applied to 
the stacks by means of the set screws threaded into the outer ends of the boxes and drawn up with lock nuts. The yoke 2 is provided with a saddle upon which rests the cable in which the tension is to be measured. At the outer ends of the frame are two more saddles, slightly movable in a longitudinal direction (see fig. I7) set lower than the central saddle. Clamping the cable to these saddles puts a bend in it, which tends to straighten when load comes on the cable and produces pressure on the central saddle. This deflects the spring and changes the resistance of the stack of plates, that of the stack in the direction of pressure being decreased and the other increased.

Figure 17 shows a complete view, back and front, of the assembled instrument, a three-conductor lead being used to connect the carbon stacks to the indicating device. Of this three-conductor lead one conductor goes to each of the outer ends of the two stacks, the third being common to the inner ends. The stacks and leads are carefully insulated from the frame. The span covered by the instrument shown is 12 inches; the bend in the cable is one-eighth inch. The pressure on the spring, therefore, is about 2 per cent of the tension of the cable.

The instrument is calibrated by clamping it to a standard size of stay cable, suspending weights from the end of the cable and taking readings. A typical curve for three sizes of cable is shown in Figure I8. It is there seen that substantially a straight line is obtained. It will be noted, however, that the curve for the one-quarter inch cables does not pass through zero, nor does it coincide with the curve for the smaller cables. This arises from the stiffness of the cable, which produces a deflection by the process of bending the cable with no load on it. On the smaller sizes this effect is negligible, but on the larger sizes it must be taken into account.

The chief sources of error in making measurements of the tension in cables lie in the stiffness of the cable, in distortion due to kinks or bends, and in more or less friction in the instrument due to sliding as the cable elongates under load. The first two may cause errors in initial readings, but these can be eliminated to a large extent by care. The stiffness of the cable, or its resistance to bending, can be taken account of in the calibration, because cables of the same size and material are quite uniform in this respect. The calibration curve passes above the zero point by an amount proportional to the bending effect. The effects of distortion can be made negligible by checking the initial tension 
in each cable with some form of tensiometer and then moving the stress indicator about until the correct initial reading is shown. Once this adjustment is made any change of tension will be properly recorded. The friction due to sliding contacts gives rise to a hysteresis loop, so that readings of decreasing tension are somewhat different from those of increasing tension. In the instruments so far built this hysteresis effect makes a difference of about 2 per cent in the upper part of the curve. However, if readings are confined to increasing loads and reasonable care is

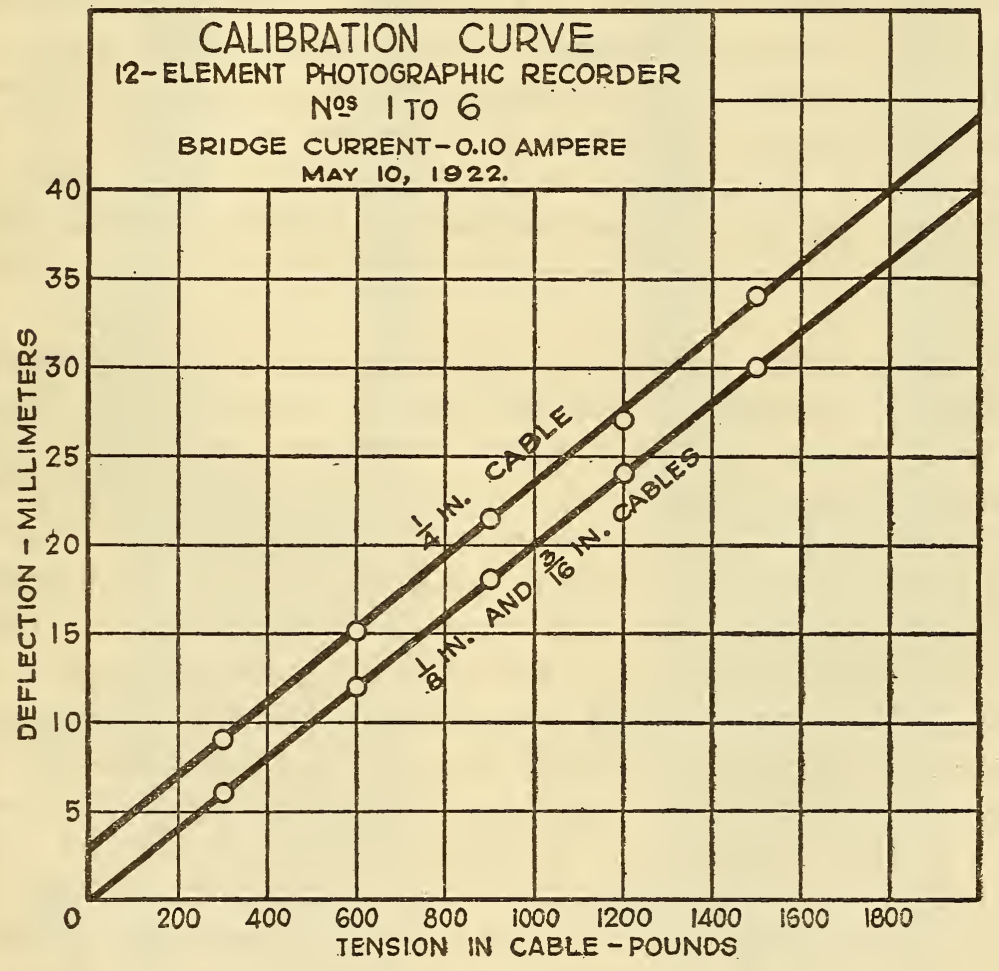

FIG. I8.

used in clamping the instrument to the cable, tensions may be measured within 5 per cent, which is probably as great an accuracy as could be expected under the conditions of measurement.

\section{STRAIN INDICATOR FOR RIGID MEMBERS.}

The details of a strain indicator for rigid members are shown in Figure $I g$ in which $I$ is a steel frame formed from a solid piece, and 2 a cantilever of nonuniform cross section which is an integral part of the frame, the upper end being fixed and the lower end 
free. Part 3 is a rod which is threaded into the cantilever and drawn up with a lock nut, the rod being free in the guide 4, which fits closely enough to prevent appreciable lateral movement. The stacks of rings are assembled on each side of the cantilever, with a three-conductor lead connecting the stacks to the indicating device. The steel end pieces forming the inner ends of the stacks rest on pivot points in cups in the cantilever, the bottoms of the cups being as close to the neutral axis of the cantilever as practicable. The thickness of the metal between the cups is about one sixty-fourth of an inch. At the top are binding posts at a gap in the conductor common to both stacks, which allows an electrical instrument to be inserted for purposes of adjustment when clamping the instrument to a member under test. At the outer end of the rod is a block with two nuts which serve to adjust the position of the cantilever and also clamp the block to the rod. The span covered by the instrument shown is 8 inches.

In operation the indicator is attached to a member as illustrated in Figure 20, the sharp steel points shown at either end in Figure I9 being forced into small punch marks in the metal to hold against slippage because some force is required to move the cantilever, and if the stress is vibratory the inertia of the clamps and gauge itself may give rise to considerable forces. The clamping is done with the nuts at the outer end of the rod loose. These are later drawn up in such a way as to bring the cantilever to its initial position, as shown by the indicating instrument. As stress comes on the member the length increases or decreases, as the case may be, and the rod and cantilever move relatively to the frame. Part of this displacement is communicated to the stack of rings, changing their resistance. The ratio of displacement-that of the member to that of the stacks-in the instrument shown is about Io to I. This ratio can be changed by changing the relative positions of the rod and the stacks of rings.

The force required to operate the instrument depends largely upon the resistance of the cantilever to bending. To make this as small as practicable, there is a relief cut in the cantilever near its fixed end. In any case the force required need not exceed ro pounds, which is a very small part of the total stress involved.

A typical calibration curve is given in Figure 2I, which shows the performance in both tension and compression with reversal of stress. The method of calibration is to clamp the instrument to a frame having a movable block, one end of the instrument being 


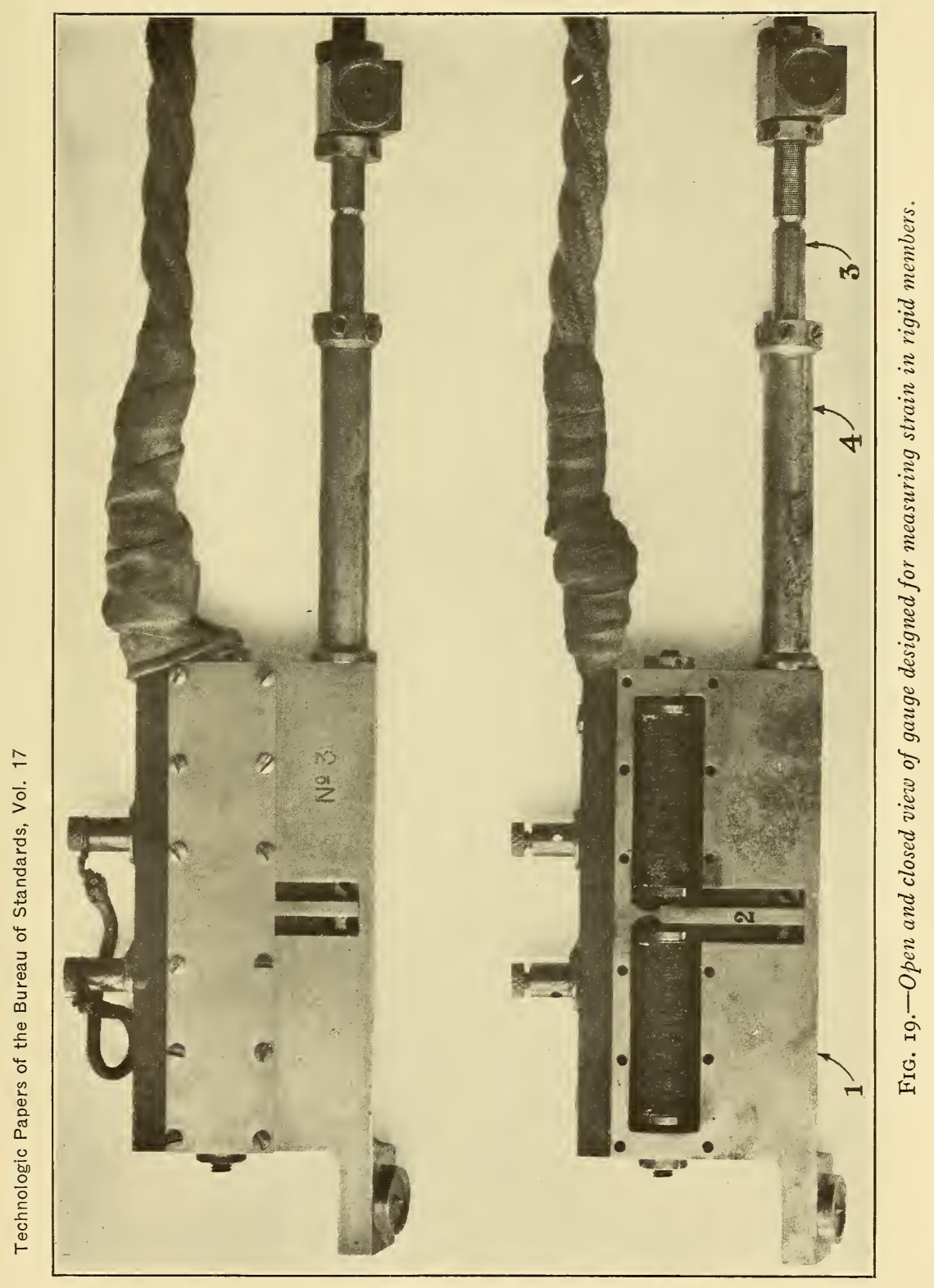




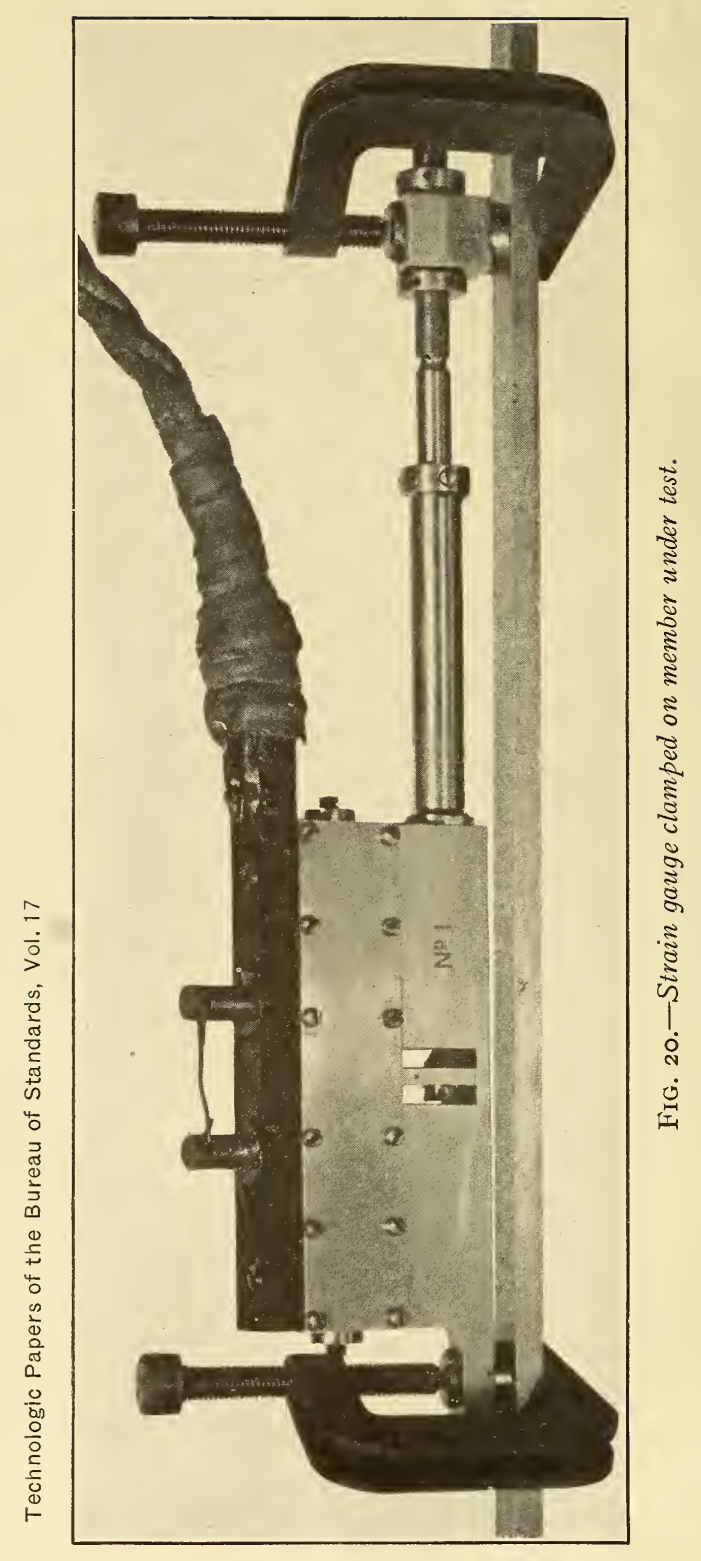


clamped to the frame and the other to the block. By moving the block, displacements measurable by a graduated screw can be communicated to the cantilever and corresponding readings made on the indicating device. Calibrations of this sort have been made on numerous occasions on devices made at the Bureau of

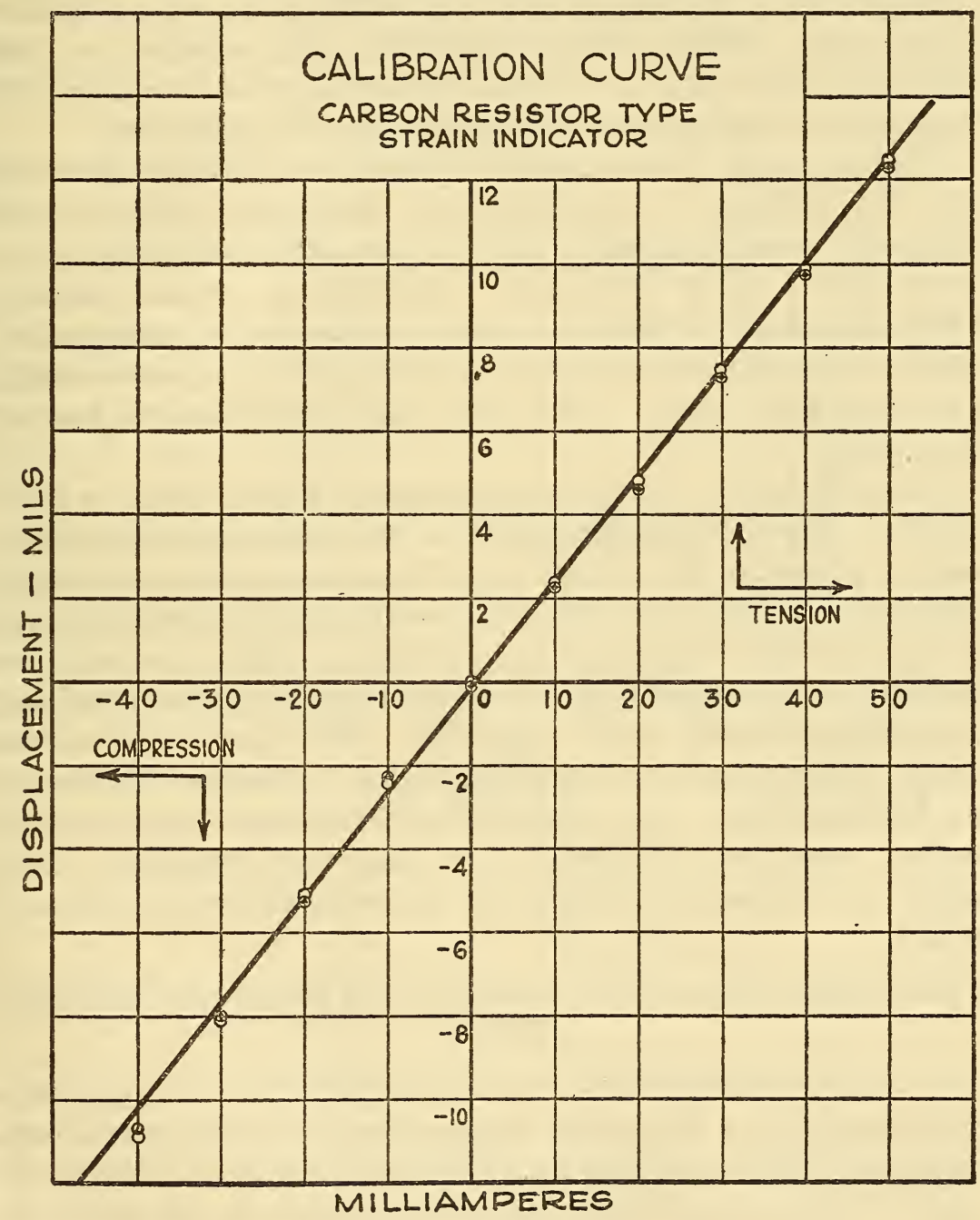

FIG. 2I.

Standards, especially for the purpose of calibrating strain gauges, and show that with great care results can be obtained with errors not greater than 0.5 of I per cent, with ordinary care not greater than 2 per cent, and under unfavorable conditions not greater than 5 per cent. All of the work so far done indicates that the possible $63245^{\circ}-24-3$ 
upper limit of accuracy of the instrument has by no means been attained. At present the accuracy of the results seems to be determined in considerable measure by the errors of the instruments used in the indicating device, which may be kept within I per cent with some of the more inexpensive instruments, and be reduced to a fraction of I per cent with instruments of better construction. With ordinary handling, the stability of the calibration bears out in marked degree the indications given by the results of tests on carbon resistors previously discussed.

Referring again to the curve in Figure $2 \mathrm{I}$, it will be observed that the readings on increasing and decreasing displacements practically coincide; that is, there is very little backlash or hysteresis. This is of advantage, especially in column testing, where on account of flexure, a part may start out in compression and then, with added increments of load, reverse and pass through zero stress into tension. Many cases may arise where this feature is of value.

The chief sources of error lie in slippage of the clamps, in temperature effects, in bending, and in the slight hysteresis that may be present. The clamps must be strong enough to produce sufficient pressure to force the steel points into the member under test, and in this way slippage can be largely avoided. In any case it is likely to be negligible except where the stresses being measured are accompanied by strong vibrations. Then the weight of the clamp itself becomes an important factor. Whether the clamps are holding or not can generally be determined from the zero reading once the instrument is in place and adjusted. Hysteresis and temperature effects can be taken care of in the calibration.

\section{ELECTRICAL CIRCUITS FOR INDICATING OR RECORDING MEASURE- MENTS.}

As mentioned in the first part of this paper, the carbon stacks are connected in a Wheatstone bridge circuit in the manner shown diagrammatically in Figure 22. The two branches of the circuit consist of the carbon stacks and leads in series on the one hand and the resistance $R_{1}, R_{2}$, and $R_{3}$ on the other. $R_{1}$ and $R_{2}$ are fixed resistances, while $R_{3}$ is a slide wire resistance with a movable contact by means of which a fine degree of balance of the bridge is obtainable. The indicating or recording instrument which may be a milliammeter or oscillograph element, is connected between the midpoint of the carbon stacks and the movable contact 
on $R_{3}$. Current is sent through the bridge circuit from the battery at the left and kept at some suitable constant value by means of the variable resistance $R_{4}$. In order to obtain the maximum effect from any change in the resistance of the stacks, the resistances $R_{1}$ and $R_{2}$ are made as nearly equal as practicable to the combined resistances of the stacks of rings and leads which oppose them. The resistance $R_{3}$ is from Io to I5 per cent of the fixed resistances in series with it.

In use the bridge is closely balanced either in the original adjustment of the carbon stacks, as in the load indicator for flexible members, or by adjustment of the stacks to zero position, as in the strain indicator for rigid members. Final balance is made by a slight movement of the movable contact on $R_{3}$. As strain comes on the member the resistances of the stacks are changed, upsetting the balance and causing deflection of the bridging instrument. As long as the current taken by the bridging instrument is small com- VOLTS pared with the total current the deflections will be proportional to the total change of resistance of the stacks, and since this is proportional to the displacement the ultimate result is to produce

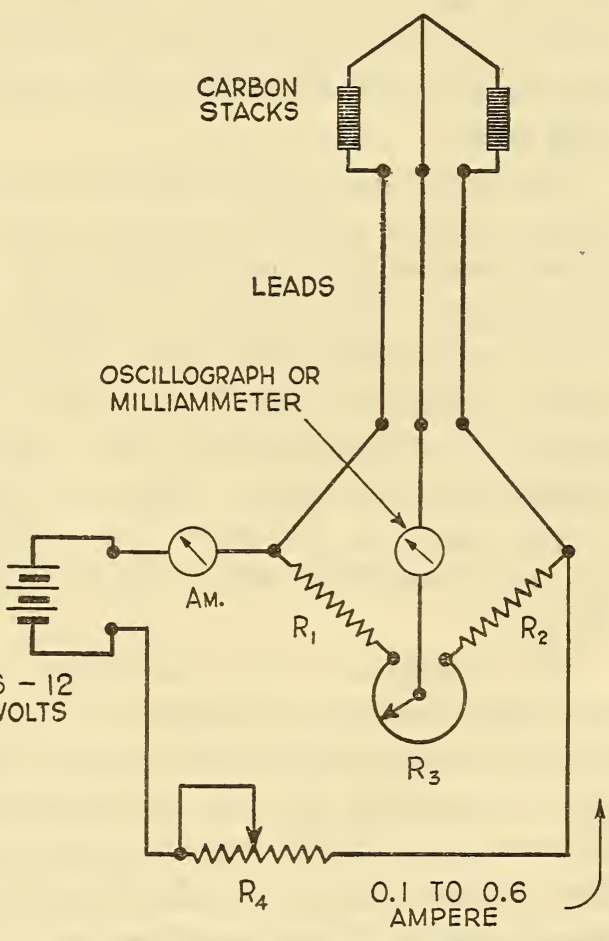

FIG. 22.-Diagram of circuit of practical form of strain gauge.

deflections of the bridging instrument that are proportional to the displacement. Thus there is obtained a calibration curve which is sufficiently near to a straight line for engineering purposes. By proper adjustment of current and the resistance of the bridging instrument the arrangement can be made direct reading, which does away with curve sheets entirely.

The total current through the bridge circuit may be anything up to several amperes, although it has been found that above about 0.6 ampere for the types of resistors so far used there are variations of resistance due to heating of the carbon. While these 
variations are small, they are undesirable and are kept as small as practicable by using the least current that can be used effectively. For many purposes currents of 0.6 ampere or less are ample, although where stresses of high frequency are concerned it is necessary to use larger currents because of the lack of sensitivity of the high-frequency oscillograph elements which must be used for recording. Since the current divides almost equally between the two branches of the bridge, a total current of 0.6 ampere gives rise to the liberation of energy in a stack of I-ohm resistance at a rate of about 0.09 watt. Where very accurate results are desired, this rate of liberation of energy is about the maximum that can be allowed, although much larger rates are allowable in certain cases.

The leads from the carbon stacks to the other portion of the bridge circuit may be of almost any length, but the resistance should not exceed that of the stacks because of cutting down the sensitivity. Leads of No. 16 copper wire Ioo feet long have been used successfully, but longer leads of larger size could also be used. Since the length and size of the leads are determined largely by the resistance of the carbon stacks, it is desirable to make the resistance of these as great as practicable. Experiments made so far show that resistances up to Ioo ohms are readily obtainable, which permit the use of leads of almost any length.

The resistance of the indicating or recording instrument with its leads should, in general, be approximately the same as that of one of the arms of the bridge circuit, although there may be great variations in this, depending upon the sensitivity of the instrument and the type of measurements that are being made. For steady stresses a milliammeter having a resistance of $I$ to 3 ohms and a full-scale deflection of 10 to 30 milliamperes will generally be satisfactory, whereas in measuring vibratory stresses it may be necessary to go to an oscillograph element having a natural frequency of $\mathrm{I}, \mathrm{O0O}$, a resistance of $\mathrm{I} .5 \mathrm{ohms}$, and a current sensitivity of 20 milliamperes per centimeter deflection. Instruments of both types have been used, and, in general, it is necessary to choose an instrument suited to the particular work in hand.

It should be noted here that calibration is made at some constant value of the current in the bridge circuit, and since the deflections of the bridging instrument are directly dependent upon the value of this current it becomes necessary to keep the bridge current accurately adjusted in order to insure accuracy in the 
results. With a storage battery as a source of current this is easily done and requires little attention, but is a factor which should be especially emphasized.

\section{RANGE OF SENSITIVITY.}

With the electrical circuits shown in Figure 22 there is possible a very great range of sensitivity, which for some kinds of work is very desirable. In the first place, the total bridge current can generally be varied from about o.I to o.6 ampere, which gives a ratio of $I$ to 6 , since the deflections of the bridging instrument are directly proportional to the total bridge current; that is, in a laboratory set designed for measuring a maximum of 0.012 inch displacement with o.I ampere in the bridge circuit, it is possible to obtain full deflection of the bridging instrument with 0.002 inch displacement by increasing the total current to 0.6 ampere. In the second place, by the provision of spare parts the ratio of reduction of the instrument itself can be changed, as in an indicator for rigid members the span can be changed, or the relative positions of the stacks of rings and the point of application of the displacement. Thus, with a single instrument it is possible to vary the range of measurement by a ratio of 20 to I or more.

\section{FIELD AND LABORATORY TESTS.}

\section{AIRPLANES.}

The practical use of the devices described herein has, of course, been limited, but there has been enough done with them to prove them of great value in making measurements both in the field and laboratory. The type for flexible members has been tried on several occasions on airplanes of the Navy Department, and in both the indicating and recording forms have given steady and reliable operation, showing plainly the magnitude of the loads in the stay cables under different conditions of the plane in flight. There was no effect from the vibration of the plane that tended to interfere with the readings. In fact, laboratory tests have shown that vibration of the cable is of service in doing away with the effects of friction due to sliding of the cable as it elongates. A photographic recorder, one view of which with its cover removed is shown in Figure 23, has been built for airplane use. With it I 2 simultaneous records can be made of the loads in the stay cables of a plane, which is a sufficient number to cover one entire 
wing. Records of this kind will be valuable in checking the stress diagrams used in airplane design which have not hereto fore been checked by actual simultaneous measurements of all of the stay cables in a wing.

\section{AIRSHIPS.}

The type for rigid members has found extensive use in laboratory work in testing airship girders. A large number of these girders were tested, and strain-gauge measurements at as many points as practicable were desirable. A group of six carbon resistor gauges was set up, the six separate bridge circuits being assembled on one panel, so the operator had before him constantly an index to the performance of the material at six points in the member under test. The readings were made rapidly, milliammeter readings only being necessary, and resulted in a great saving of time as compared with the use of dial gauges, which would necessitate continual passing from one point to another and checking against a gauge bar to see that correct readings were obtained. The carbon resistor gauges have the advantage that they remain in place throughout the test, and in that way measurements by individuals are more likely to be uniform than they would otherwise be. The readings of the carbon resistor gauges were checked by short-span dial gauge measurements, by overall strain measurements, and by frequent calibration and were found as accurate at least as the best dial gauges and with the additional advantage of a great saving of time and fatigue of the operator.

A test has also been made of members of an airship under construction during the initial inflation of one of the gas bags. Readings were taken at six points near a joint in the frame located 70 feet above the floor of the hangar, leads 50 feet long being used, which enabled the operator to work on a convenient platform. Similar readings might be taken during flight with gauges located at parts of the frame widely separated and difficult of access, with the indicating panel placed where it could be observed at all times.

\section{BRIDGES.}

Laboratory application has been made in testing steel plate girders, I2 gauges being read by one operator rapidly and conveniently. Some preliminary work has also been done on steel bridges, simultaneous records having been taken on a railroad bridge where heavy trains were passing at frequent intervals. 
Technologic Papers of the Bureau of Standards, Vol. 17

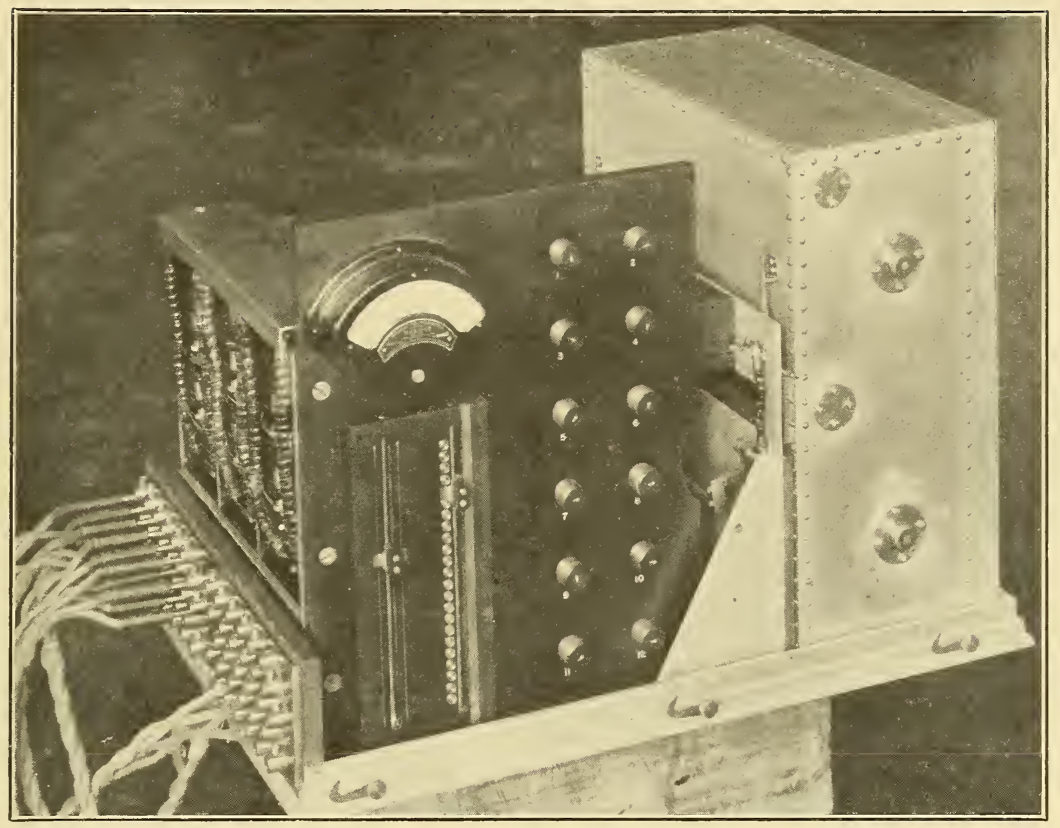

FIG. 23.-I2-element recorder with cover removed.

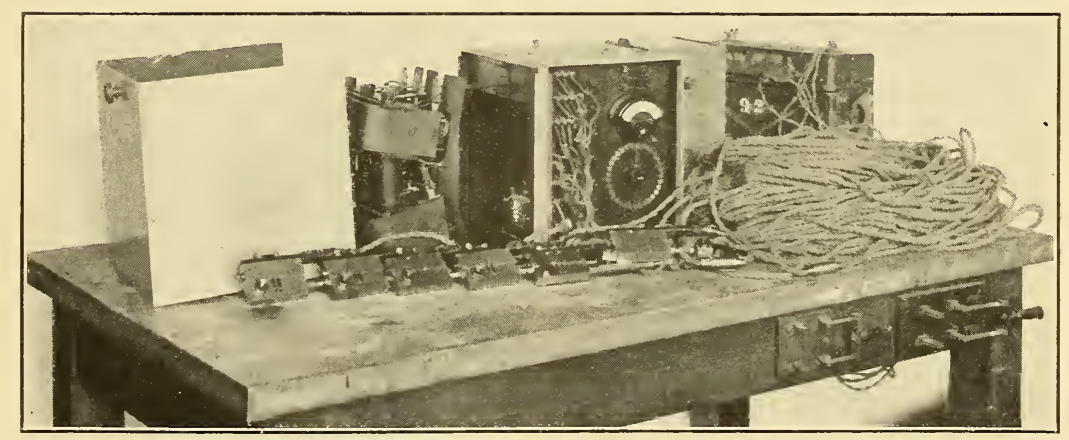

FIG. 25.-Assembly view of 6-element recorder and six ganges with connecting cables. 
Technologic Papers of the Bureau of Standards, Vol. 17

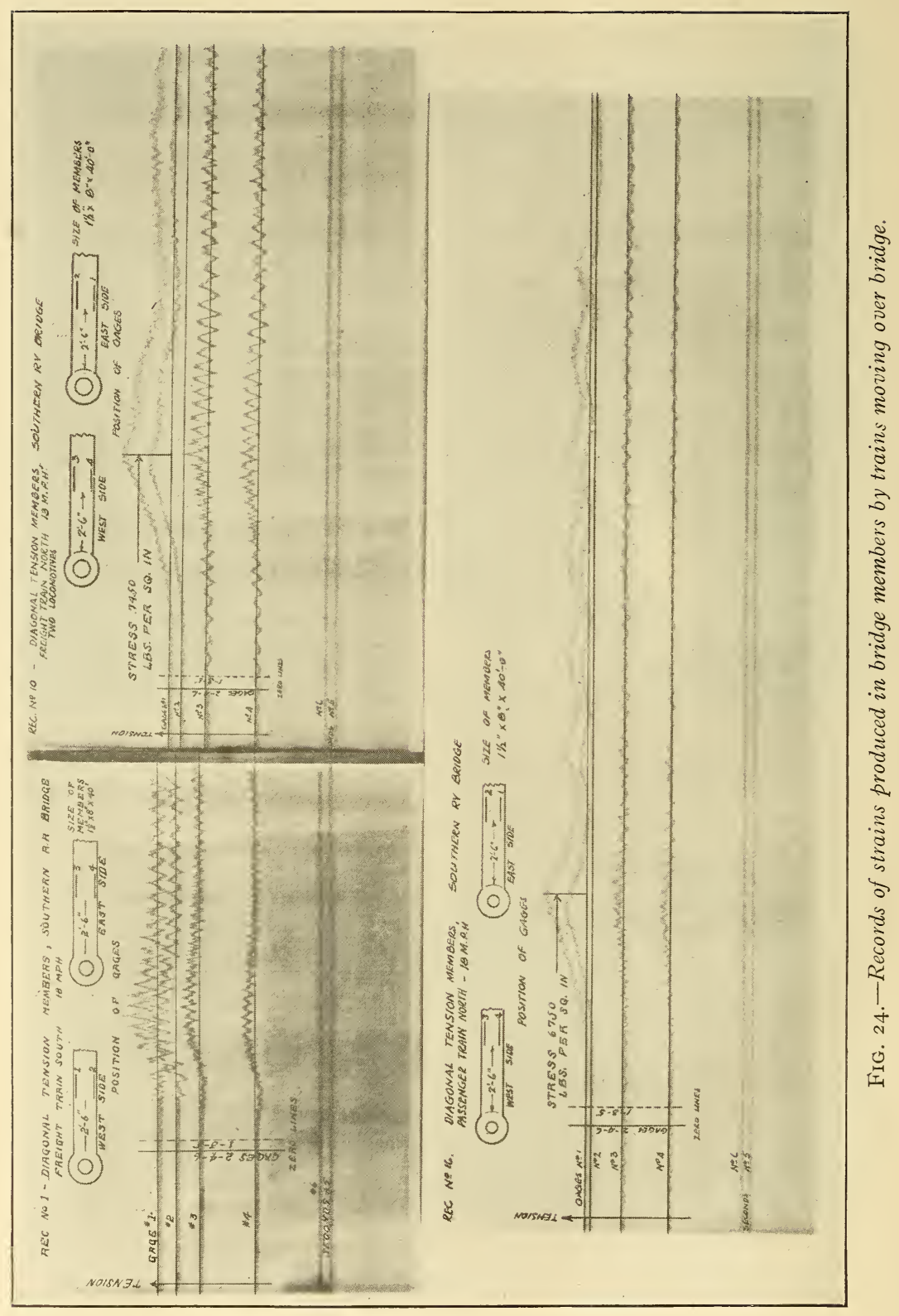


In Figure 24 are shown some of the records, and while these were taken solely with the view of ascertaining the performance of the apparatus and do not constitute a sufficient basis for analysis of the distribution of stress in the structure they may be taken as a fair indication of what may be expected in the way of vibrations and the character of the stresses involved.

Four traces are shown taken on corresponding diagonal tension members on opposite sides of the structure, the gauges being interchanged in the middle of the series to ascertain whether different gauges in the same place would show similar performance. Trace No. 5 shows I-second intervals.

Record No. I shows the effects of a freight train going south at I 8 miles per hour, gauges Nos. I and 2 being on the same side of the bridge as the train, and therefore showing the greatest stress. Record No. Io shows the effects of a freight train drawn by two locomotives going north at $\mathrm{I} 3$ miles per hour, the gauges having been interchanged so Nos. I and 2 were again on the same side as the load. Record No. I6 shows the effects of a passenger train going north at I 8 miles per hour. In records I and Io only part of the passage is shown, the recorder having been stopped after the engine had crossed the span. In every case the trace returned to the zero line, however, as shown in record No. I6. Vibrations continued until long after the train had passed, there appearing to be a transfer of energy from one part of the bridge to another for a considerable time.

The traces were made with an oscillograph recorder, shown in Figure 25, the elements of which had a natural frequency of about 600 cycles per second. These were damped sufficiently to come to rest in approximately $\mathrm{I} / 2$ cycles, the damped frequency being about 300 cycles per second. The fact that carbon stacks will reproduce mechanical vibrations in true proportion up to more than 800 cycles per second having already been shown, there is little doubt that the vibrations of the traces in Figure 24 are those of the members under test, rather than sympathetic vibrations of some part of the measuring apparatus. In this connection it should be noted that the vibrations of the parts of the gauges themselves were forced, so the natural period of the tongue and rod would have no effect. The frequencies shown range from 2 to 50 cycles per second, and while their magnitude is not large in the present case, other cases may arise where the vibratory stresses are of sufficient magnitude to warrant serious study. 
In the records shown there are six traces, four being traces of gauge measurements, one of time intervals, and one inactive. The six, however, could be used for gauge measurements with an additional one for timing, which would allow simultaneous measurements to be made at six points in a bridge. This number can be increased, and work in the direction of constructing an oscillograph recorder which will enable simultaneous measurements at 12 points in a structure will be undertaken, as in the analysis of bridge structures simultaneous measurements at a large number of points are desirable.

\section{DYNAMOMETERS.}

One instrument has been put into service measuring the pull at the pressure arms of an electrodynamometer used for testing brake-band material in which there was a great deal of vibration, so much that reading a spring balance was tedious and the results inaccurate. The electrical device showed steady operation and allowed graphical recording, which released the services of the operator for other duties.

\section{PRESSURE GAUGES.}

So far experimental applications have been made to the measurement of air pressures ranging from o to $300 \mathrm{~mm}$ of mercury and to oil pressures up to $40,000 \mathrm{lbs}$./in. ${ }^{2}$

\section{PRACTICABLE APPLICATIONS.}

The carbon-resistor type of instrument is adaptable to the measurement of forces from any source, provided the force to be measured is great enough to operate a suitably designed device for communicating the necessary pressure to the carbon resistors. While no attempt has been made to determine the lower limit of force with which satisfactory results can be obtained, the indications are that with multiplying levers and allowing the necessary movement forces of the order of tenths of grams can be measured.

In the measurement of displacements the movement is fixed, so that, in general, the smaller the displacement to be measured the greater the force required because of the smaller ratio of the multiplying lever. Where displacements in structural materials are to be measured, the total force is generally great enough, so that the part required to operate the gauge is an inappreciable part of the total, in no case exceeding Io or 12 pounds. In the 
case of other displacements, however, as in parts of machinery or apparatus, the available force may be small, and consequently may be troublesome to apply.

Where liquid or gas pressures of low values per unit area are involved-that is, values of the order of a few millimeters of mercury-a flexible diaphragm can be used which can be so proportioned as to give the necessary total force. The upper limit of pressure which can be measured is limited only by the elastic limit of the materials of which the gauge can be made.

In the measurement of forces and displacements which are vibratory in character consideration must always be given to the question of natural frequency of parts of the apparatus. If there are harmonics present in the measured phenomenon which in frequency are equal to or greater than that of any of the parts of the apparatus, the effect of the harmonics will be exaggerated or masked, depending on their relative values. In general, for satisfactory results the natural frequency of all parts of the appparatus should be at least double that of the highest harmonic of the disturbance under investigation. This may impose troublesome limitations where the forces involved are small.

In the measurement of displacements and pressures due to impacts and explosions the question of shock must be taken into consideration. While not much research work has been done in this direction, the indications are that instruments can be devised that will give satisfactory results under conditions that do not cause too severe lateral shocks to the stacks of plates. Longitudinal shocks apparently are received without difficulty, but lateral shocks are more severe in their effects. This was found to be the case with a gauge designed for measuring pressures in guns when fired. The gas pressure seemingly had no detrimental effect, but the whip of the gun under recoil caused the stacks to shift.

Bearing the foregoing facts in mind, it seems practicable to adapt the carbon resistor to a considerable number of classes of measuring devices, including strain and stress gauges, pressure gauges, manometers, accelerometers, dynamometers, weighing machines, and other devices, with satisfactory results, especially where remote reading or recording and simultaneous measurements at widely separated points are desirable features.

In field work portability is an important consideration, and here the carbon-resistor type of instrument has much in its favor. The I2-element recorder for airplane work illustrated in Figure 23 
is II $1 / 2$ by I $_{2}$ by $I_{7}$ inches in size and weighs when completely equipped about 40 pounds. The 6 -element oscillograph recorder shown in Figure 25 weighs 60 pounds and is $121 / 2$ by $121 / 2$ by 23 inches in size. In addition, there are the film holder, I2-volt battery, leads and gauges, all of which can easily be carried in a light touring car.

\section{SUMMARY.}

I. The development of the carbon resistor has been carried to a point where a sufficient degree of accuracy and stability has been obtained to make it applicable to many kinds of engineering measurements. Under unfavorable conditions measurements of stresses, forces, and displacements can be made with errors not exceeding 5 per cent, while under favorable conditions measurements can be made with errors not exceeding 2 per cent, and with great care the errors need not exceed one-half of I per cent.

2. The carbon-resistor type of instrument finds its greatest field of application in the measurement of vibratory and transient forces and displacements, because it readily lends itself to photographic recording. It has also the advantage that it can be made remote reading or recording, enabling simultaneous measurements to be made at widely separated points.

3. While the greatest field of application lies in the measurement of vibratory phenomena, it finds also a wide application where steady values are to be measured, as in some kinds of laboratory testing where a number of simultaneous measurements are to be made.

4. The hysteresis effects and erratic performance heretofore observed in connection with carbon resistors have been eliminated by using mounting frames without mechanical joints, giving particular care to preparing and mounting the disks and keeping the stack always under pressure, only a small part of its total pressure-resistance range being utilized.

5. The objectionable nonlinear displacement-resistance characteristic typical of the carbon resistor has been eliminated by the use of two stacks of plates in each instrument, in one of which the resistance is increased and in the other decreased through the same range of values. It has been found that this arrangement gives substantially a linear displacement-resistance characteristic.

6. In the measurement of vibratory stresses it has been found that as far as the stacks themselves are concerned the pressure- 
resistance characteristic may be depended upon at rates of vibration at least as high as 840 cycles per second.

7. Applications so far made include the measurement of stress in airplane stay cables during flight, the laboratory testing of structural members for airships and bridges, and the measurement of stresses in steel bridges due to live loads. Application has also been made to dynamometers for testing brake-lining material and to recording manometers.

8. Two types of photographic recorders have been built, one suitable for measuring vibratory stresses up to roo cycles per second and another for stresses of low frequency.

WAsHingTon, July I6, I 923. 



\section{INDEX TO VOLUME 17.}

A.

Page.

Acidity of oils

Aeronautic instruments

Aircraft instruments......

Air pump, reciprocating, rate cf exhaustion

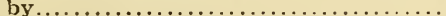

Air-speed indicators . . . . . . . . . . . . .

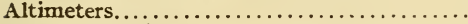

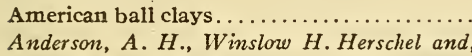

Reclamation of used petroleum lubricating oils.

B.

Ball clays

Barographs

Bates, P. H Roy N Young, and Paul Rapp, Tests of caustic magnesia made from magnesite from several sources...............

Batteries, sulphation of plates.............

Berry, Walter L., I. V. Brumbaugh, J. $H$.

Eiseman, G. F. Moulton, and G. B. Shawn, Relative usefulness of gasses of different heating value and adjustments of burners for changes in heating value and specific

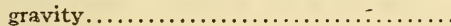

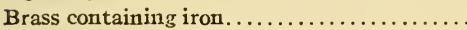
magnetic susceptibility............

Brightness of white papers...............

Brittleness of malleable cast iron

Brumbaugh, I. V., Walter M. Berry, J. H. Eiseman, G. F. Moulton, G. B. Shawn and, Relative usefulness of gasses of different heating value and adjustments of burners for changes in heating value and specific gravity.

Buckingham, Edgar, Rate of exhaustion of a closed tank by a reciprocating air pump.

Burgess, George $K$., and $G$. Willard Quick, Thermal stresses in steel car wheels........

- - - A comparison of the deoxidation effects of titanium and silicon on the properties of rail steel.

\section{C.}

Carbon monoxide in products of combustion..

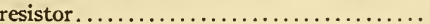

Car wheels, steel, thermal stresses in........ Cast iron, malleable, embrittlement of...... heat treatment to reduce brittleness. wet-process enameling of.

Cast red brass containing iront..........

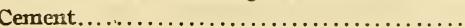

Chrotiograph, recording, for inverse-rate method of thermal analysis . ............. Classification of modern high-speed tool steels.

Clay, plastic flow of

Clays, methods of measuring plasticity of

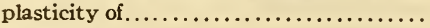
properties of
Page.

Clocks, aircrait..................... 447

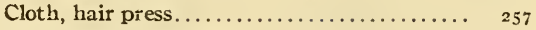

Color of white papers.................. 667

Commercial micrometers................ 125

Compasses, aircraft............... 447

Concrete slab beams reinforced diagonally ... 297

Cutting tests, high-speed steels........... $\quad{ }_{18}$

D.

Danielson, R. R., and H. P. Reinecker, Wetprocess enamels for cast iron. ............ 695

Deoxidation of rail steel............... $\quad 5_{58}^{8 I}$

Detector for water vapor detector......... $6_{37}$

Determination, magnetic, of iron in brass.... I

Dial micrometers.................... I 125

Dynamometer tests................. 559

E.

Eccentric loading of hollow-tile walls........

Effect, time on strains in concrete and rein-

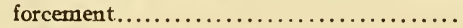

Eiseman, J. H., Walter M. Berry, I. V. Brum-

baugh, G. F. Moulton, G. B. Shawn and,

Relative usefulness of gasses of different

heating value and adjustments of burners

for changes in heating value and specific

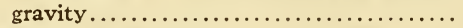

Elasticity of wire rope. ................

Electrical strain gauge. ................

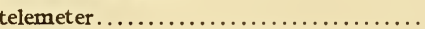

Electrolytic water vapor detector...........

Embrittlement of malleable cast iron ........

Enameling, cast iron, wet-process.......... wet-process of cast iron . . . . . . . . . . .

Enamels, cast iron, wet-process............ ground coat, for cast iron............. single coat, for cast iron............... sintered ground coat. . . . . . . . . . . . . wet-process for cast iron................ white, wet-process, for cast iron......... Endurance, high-speed lathe tools..........

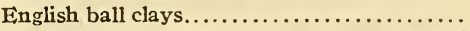
Exhaustion by reciprocating air pump, rate of Expanded metal, tests of slabs reinforced with F.

Flat slab, strain gauge test............... French, $H$. $J$., A recording chronograph for the inverse ratemethod of thermal analysis. - and Jerome Strauss, Lathe breakdown tests of some modern high-speed tool steels.

G.

Gas burners, method of testing........... $I_{5}$

Gas efficiency of utilization.............. $1_{5}$

Gasoline-flow meters, aircraft.......... 447

Gasoline gauges, aircraft.............. 447

Gas temperature thermometers, aircraft..... 447 
Grading white papers for color............ 667

Green, $T . W$., and A.H. Stang, Stresses in a few welded and riveted tanks tested under hydrostatic pressure....................

Ground-speed indicators.................

$\mathrm{H}$.

Hair press cloth

Hall $F$. $P$. Methods of measuing the ticity of clays.

Hathcock, Bernard D., Herbert L. Whittemore and, Some compressive tests of hollow-tile walls. .

Heat treatment of high-speed steels......... of malleable cast iron................

Herschel, Winslow H., and A.H. Anderson, Reclamation of used petroleum lubricating oils.

High-speed steel, lathe tests..............

Hollow-tile slab, loading test............... walls, strength of .....................

Holt, W. L., and P. L. Wormeley, Dynamometer tests of automobile tires.............

Houston, Paul L., and D. R. Miller, A study of commercial dial micrometers for measuring the thickness of paper.............. Hunt, Franklin L., Aeronautic instruments.. Hydrogen leak detectors, aircraft.......... Hydrostatic tests of steel tanks............

\section{I.}

Inclinometers. ..................

Inclusions, iron in brass. . . . . . . . . . . . . . Interfacial tension of oils................... Inverse-rate method of thermal analysis, recording chronograph for.................. Iodine pentoxide apparatus for carbon mon-

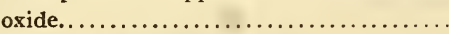
Iron, cast, enameling of ................. wet-process enameling of............. in brass........................... in brass microstructure................. in cast red brass...................... inclusion in brass.

\section{L.}

Larson, Louis J., and Serge N. Petrenko, Loading test of a hollow tile and reinforced concrete fioor of Arlington Building, Washington, D. C.

Lathe tests, high-speed steels Ledig, P. G., and E. R. Weaver, Detector for water vapor in closed pipes.

Lofton, R. E., A measure of the color characteristics of white paper................. Loading test of reinforced hollow-tile slab.... L ubrication of wire rope..................

\section{M.}

McGowan, F. R., and C. W. Schoffstall, Tentative standard test methods and percentages of oil and moisture in hair press cloths.

McCollum, Burton, and O.S. Peters, A new electrical telemeter.

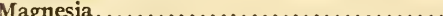

Magnesite. permeability of brass containing iron... I susceptibility of brass containing iron... I Malleable cast iron, embrittlement of ....... 677 heat treatment to reduce brittleness. 667 Manometers, aircraft................. 447

Marshall, Leslie H., Embrittlement of malleable cast iron resulting from heat treatment. - and R. L. Sanford, Magnetic susceptibility and iron content of cast red brass. . Measuring plasticity of clays, methods of.... Method, inverse rate, of thermal analysis, recording chronograph for...............

Methods of measuring plasticity of clays....

Method of testing oils.....................

Micrometers...........................

Microstructure of brass containing iron.....

Miller, D. R., Paul L. Houston and, A study of commercial dial micrometers for measuring the thickness of paper............. $\quad 125$ Modulus of elasticity of wire rope.......... 227 Moisture content (press cloth) ............ 257 Moulton, G. F., Walter M. Berry, I. V. Brumbaugh, J. H. Eiseman, G. B. Shawn and, Relative usefulness of gases of different heating value and adjustments of burners for changes in heating value and specific gravity ............................

N.

Navigation instruments, aircraft........... o.

Oil content (press cloth) ................. $\quad 257$ pressing........................... ${ }_{257}$

Oils, interfacial tension of . . . . . . . . . . . methods of testing.................. 93 organic acidity of .................... 93 reclaimed......................... 93 refining............................. 93 tension, interfacial.................. 93 test methods........................ Oxygen instruments, aircraft............ 447

Paper, color of white................... $66 \%$ finish of $\ldots \ldots \ldots \ldots \ldots \ldots \ldots \ldots \ldots, 66_{7}$ micrometers...................... I25

Performance, modern high-speed steels...... $\quad 183$

Permeability, magnetic, of brass containing iron ................................

Peters, O.S., and Burton McCollum, A new electrical telemeter.....................

Petrenko, Serge N., Louis Larson and, Loading test of a hollow tile and reinforced concrete floor of Arlington Building, Washington, D. C....................... 405

Plasticity, methods of measuring........... 345 of clays........................... 345

Power loss........................... $\quad 559$

Pottery materials, ball clays.............. ${ }_{153}$

Press cloth ......................... ${ }_{257}$

Pressure gauges, aircraft............... 447 tests of steel tanks.................. 645

Properties, high-speed steels.............. $\quad{ }_{18}$ of ball clays....................... ${ }^{153}$ 
Quick, G. Willard, and George K. Burgess, A comparison of the deoxidation effects of titanium and silicon on the properties of rail steel.

,-- Thermal st resses in steel car wheels.

R.

Rail steel, titanium and silicon deoxidation of ...........................

Rapp, Paul, P. H. Bates, and Roy N. Young, Tests of caustic magnesia made from magnesite from several sources.

Rate-of-climb indicators. . . . . . . . . . . . . .

Rate of exhaustion by reciprocating air pump.

Rate of sulphation.

Reclaimed oils.

Recording chronograph for inverse rate method of thermal analysis..............

Recording instruments, aircraft............

Refining oils.

Reinecker, H. P., and R. R. Danielson, Wetprocess enamels for cast iron.............

Reinforced concrete building test.

Reciprocating air pump, rate of exhaustion

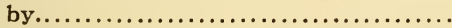
Ritchie, L. M., G. W. Vinal and, A new method for determining the rate of sulphation of storage-battery plates...........

Riveted tanks, stresses in

$$
\text { S. }
$$

Sanford, R. L., L. H. Marshall and, Magnetic susceptibility and iron content of cast red brass. .

Schoffstall, C. W. F. R. McGowan and, Tenta tive standard test methods and percentages of oil and moisture in hair press cloths....

Seely, Fred B., Willis A. Slater and, Tests of heavily reinforced concrete slab beams: Effect of direction of reinforcement on strength and deformation. .

Shawn, G. B., Walter M. Berry, I. V. Brum baugh, J.H. Eiseman, G. F. Moulton and, Relative usefulness of gasses of different heating value and adjustments of burners for changes in heating value and specific gravity ..............................

Sheaves, effect on wire rope..............

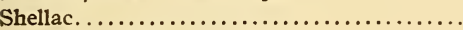
source and manufacture. ............. specifications. testing of.

silicon as a deoxidiz Skillman, Edward, Some tests of steel-wire

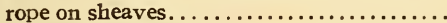

Slab beams, reinforced diagonally..........

Slab, hollow tile and reinforced concrete, test.

Slater, Willis A., and Fred B. Seely, Tests of heavily reinforced concrete slab beams; Effect of direction of reinforcement on strength and deformation. ....................

Sortwell, $H: H .$, American and English ball

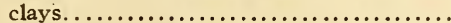
Susceptibility, magnetic, of brass containing

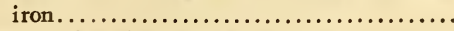
Sulphation of storage-battery plates........ Stang, A. H., and T.W. Green, Stresses in a few welded and riveted tanks tested under hydrostatic pressure.
Statoscopes. Page.

Steel car wheels, thermal stresses in......... tanks, stresses in ........ 367 titanium and silicon deoxidation........ $58 \mathrm{x}$

Steele, Lawrence L., Percy H. Walker and,

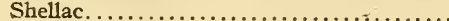

Storage batteries....................... Strain-gauge measurements on steel tanks. . test of reinforced concrete flat slab...

Strauss, Jerome, H. J. French and, Lathe breakdown tests of some modern high-speed tool steels.

Strength of hollow tile wails.............

Stresses in in steel tanks....................... 645 thermal, in steel car wheels............ ${ }_{367}$

Strut thermometers, aircraft............. 447

\section{T.}

Tachometers, aircraft.................. 447

Tanks, stresses in steel................. $\quad 645$

Telemetric devices..................... $\quad 7_{737}$

Tension, interfacial, of oils............... 93

Testing ball clays....................... ${ }_{153}$ of shellac.........................

Tests of steel car wheels................... ${ }_{3}{ }_{3}$ of welded and riveted tanks.......... 645

I17 Thermal analysis, recording chronograph for inverse rate method of ................. 245 stresses in steel car wheels.............. ${ }_{367}$

Thermometers, aircraft.................. 447

Thickness.............................. I25 of paper...........................

Tile slab, loading test.................. $\quad 405$ walls, strength of ....................

Time, effect on strains in concrete......... 405

Tires.............................. 555

Titanium as a deoxidizer of rail steel......... $58 \mathrm{r}$

Turn indicators........................ 447

Uses of shellac $\quad$ U.

$$
\mathrm{V} \text {. }
$$

Varnish, shellac...................... 27

Vinal, G. W., and L. M. Ritchie, A new method for determining the rate of storagebattery plates.

w.

Walls, hollow-tile, strength of..............

Walker, Percy H., and Lawrence L. Steele, Shellac.

Water-soluble (press cloth) ................

Weaver, E. R., and P. G. Ledig, Detector for water vapor in closed pipes.............. $6_{37}$

Welded tanks, stresses in................. $6_{45}$

Wheels, steel car, thermal stresses in........ ${ }_{367}$

Whittemore, Herbert L., and Bernard D. Hathcock, Some compression tests of hollow-tile walls.............................. $5_{5} x_{3}$

Wire rope on sheaves.................... $\quad{ }_{227}$

Workability of clay. See Plasticity.

Wormeley, P. L., W. L. Holt and, Dynamometer tests of automobile tires...............

\section{$\mathrm{Y}$.}

Young, Roy N., P. H. Bates, Paul Rapp, and, Tests of caustic magnesia............

7

5

3

.

7

47

7

7

7

45

5

7

5

3

$8 \mathrm{I}$

